\title{
Assessment of some parameterizations of heterogeneous ice nucleation in cloud and climate models
}

\author{
J. A. Curry $^{1}$ and V. I. Khvorostyanov ${ }^{2}$ \\ ${ }^{1}$ School of Earth and Atmospheric Sciences, Georgia Institute of Technology, Atlanta, Georgia, USA \\ ${ }^{2}$ Central Aerological Observatory, Dolgoprudny, Moscow Region, Russia
}

Correspondence to: J. A. Curry (curryja@eas.gatech.edu)

Received: 16 December 2009 - Published in Atmos. Chem. Phys. Discuss.: 3 February 2010

Revised: 17 May 2010 - Accepted: 17 January 2012 - Published: 27 January 2012

\begin{abstract}
Several different types of parameterization of heterogeneous ice nucleation for cloud and climate models have been developed over the past decades, ranging from empirically-derived expressions to parameterizations of ice crystal nucleation rates derived from theory, including the parameterization developed by the authors that includes simultaneous dependence on the temperature and saturation ratio, hereafter referred to as KC. Parameterizations schemes that address the deliquescence-heterogeneous-freezing (DHetF), which combines the modes of condensation freezing and immersion freezing, are assessed here in the context of thermodynamic constraints, laboratory measurements, and recent field measurements. It is shown that empirical schemes depending only on the ice saturation ratio or only on temperature can produce reasonable crystal concentrations, but ice crystal nucleation is thermodynamically prohibited in certain regions of the temperature-saturation ratio phase space. Some recent empirical parameterizations yield clouds that are almost entire liquid at temperatures as low as $-35^{\circ} \mathrm{C}$ in contrast to cloud climatology. Reasonable performance of the $\mathrm{KC}$ ice nucleation scheme is demonstrated by comparison with numerous data from several recent field campaigns, laboratory data, climatology of cloud phase-state. Several mis-applications of the KC parameterization that appeared recently in the literature are described and corrected. It is emphasized here that a correct application of the KC scheme requires integration of the individual nucleation rates over the measured size spectrum of ice nuclei that represent a fraction or several fractions of the environmental aerosol with specific ice nucleation properties. The concentration in these fractions can be substantially smaller than that of the total aerosol, but greater than the crystal concentration measured by an experimental device. Simulations with temperature-
\end{abstract}

dependent active site area or with several IN fractions having different properties show that ice nucleation in the $\mathrm{KC}$ scheme occurs in a wide temperature range of $10-20^{\circ} \mathrm{C}$, which depends on IN properties. Simulation with a spectral bin model and correct application of KC scheme adequately describes ice nucleation via the DHetF mode and yields crystal concentrations and phase state close to those measured in the single-layer stratocumulus cloud observed in the Mixed Phase Arctic Cloud Experiment (MPACE). An assessment of some deficiencies in current parcel modeling methods and cloud chamber observations and their impact on parameterization development and evaluation is provided.

\section{Introduction}

Ice formation in atmospheric clouds influences the cloud life cycle, precipitation processes, and cloud radiative properties. The importance of cloud ice processes in global climate models has stimulated a large number of theoretical and experimental studies on this topic, but many outstanding problems remain. Further, several recent papers have compared different ice nucleation schemes with contradictory results, raising issues regarding the appropriate application of the schemes, limitations of the parcel model framework, and interpretation of cloud chamber results.

The authors of this paper have developed a theory of heterogeneous ice nucleation by deliquescence-heterogeneousfreezing, DHetF (Khvorostyanov and Curry, 2000, 2004a, b, 2005, 2009, hereafter referred to as the KC scheme). This scheme has allowed quantitative description of many features of ice formation in clouds including simultaneous dependence of the freezing of solutions on both temperature

Published by Copernicus Publications on behalf of the European Geosciences Union. 
$T$ and water saturation ratio $S_{\mathrm{w}}$. This created a platform for further improvements of the classical nucleation theory and its practical applications to the parameterization problem. In this paper, we assess the $\mathrm{KC}$ nucleation scheme along with several commonly used and recently developed empirical ice nucleation schemes, in the context of thermodynamic constraints and laboratory and field observations. Classical cloud physics defines four modes of heterogeneous ice nucleation: condensation-freezing, immersion, contact and deposition (Vali, 1985; Pruppacher and Klett, 1997, hereafter PK97). The focus of this assessment is on the deliquescenceheterogeneous-freezing (DHetF) mode, which combines the thermodynamically indistinguishable modes of condensation freezing and immersion freezing.

Over the past several decades, numerous empirical parameterizations have been developed for these modes of heterogeneous ice nucleation or their combinations, based primarily on laboratory data. Fletcher (1962), Cooper (1986), Sassen (1992), DeMott et al. (1998) suggested parameterizations of ice nuclei (IN) $N_{\mathrm{c}}(T)$ as empirical functions of temperature $T$. Huffman and Vali (1973), Huffman (1973), and Berezinsky and Stepanov (1986) offered a parameterization consisting of a power law by ice supersaturation $s_{\mathrm{i}}=\left(\rho_{\mathrm{v}}-\rho_{\mathrm{si}}\right) / \rho_{\mathrm{si}}$, where $\rho_{\mathrm{v}}$ and $\rho_{\mathrm{si}}$ are vapor density and saturated over ice density. Meyers et al. (1992, hereafter MDC92) used a continuous flow diffusion chamber (CFDC) to form the basis of an empirical parameterization of the combined condensation-freezing and deposition modes as a supersaturation-dependent only function

$N_{\mathrm{c}}\left(s_{\mathrm{i}}\right)=\exp \left(a_{\mathrm{M}}+b_{\mathrm{M}} s_{\mathrm{i}}\right)$,

with $N_{\mathrm{c}}$ in $1^{-1}, s_{\mathrm{i}}$ in $\%, a_{\mathrm{M}}=-0.639, b_{\mathrm{M}}=0.1296$. This parameterization was suggested to be valid at $-20<T<$ $-7^{\circ} \mathrm{C}$, and $2<s_{\mathrm{i}}<25 \%$, although Eq. (1) has been subsequently applied outside this parameter range (e.g., Comstock et al., 2008). Although the temperature dependence was present in the original data, MDC92 averaged it and included only the supersaturation dependence in the parameterization. A similar $s_{\mathrm{i}}$-dependent parameterization for deposition nucleation on dust particles was suggested recently by Möhler et al. (2006) based on measurements in a large expansion chamber of $84 \mathrm{~m}^{3}$.

An empirical parameterization for the immersion mode with soot, mineral dust and biological nuclei was recently suggested by Diehl and Wurzler (2004, hereafter DW04) that generalized Bigg's (1953) concept of the median freezing temperature. This parameterization was tested in the GCM ECHAM4 (Lohmann and Diehl, 2006).

Phillips et al. (2008, hereafter PDA08) developed a new empirical parameterization using MDC92 as a basis. PDA08 extended this parameterization for various $T$ - and $s_{\mathrm{i}}$-ranges and generalized the parameterization to account for the three types of freezing aerosol (dust and metallic compounds, black carbon, and insoluble organics) by appropriate scaling and integration over the surface areas of these aerosols, so that the concentration $N_{\mathrm{c}, x}$ of IN of the $x$-th kind is

$$
N_{\mathrm{c}, x}=\int_{\log [0.1 \mu \mathrm{m}]}^{\infty}\left(1-\exp \left[-\mu_{x}\left(D_{x}, S_{\mathrm{i}}, T\right)\right] \frac{d n_{x}}{d \log D_{x}} d \log D_{x},\right.
$$

where $x$ denotes any of the 3 aerosol types, $n_{x}$ is the aerosol mixing ratio, and $\mu_{x}$ is the average activated IN per aerosol of diameter $D_{x}$; and $\mu_{x}$ is proportional to $N_{\mathrm{c}}\left(s_{\mathrm{i}}\right)$ from Eq. (1) multiplied by some coefficients. For low freezing fraction, which often takes place, $N_{\mathrm{c}, x} \sim \mu_{x} \sim N_{\mathrm{i}}$ (PDA08).

DeMott et al. (1998, hereafter DM98) suggested a parameterization of the ratio $F_{\mathrm{IN} / \mathrm{CN}}$ of the concentration $N_{\mathrm{c}}$ of IN to the concentration $N_{\mathrm{CN}}$ of cloud nuclei $(\mathrm{CN})$ as a simple power law function by temperature, then

$F_{\mathrm{IN} / \mathrm{CN}}=a_{\mathrm{D}}\left(-T_{\mathrm{c}}\right)^{b_{\mathrm{D}}}, \quad N_{\mathrm{c}}=F_{\mathrm{IN} / \mathrm{CN}} N_{\mathrm{CN}}$

where $a_{\mathrm{D}}=1.3 \times 10^{-22}, b_{\mathrm{D}}=11.75$, and $N_{\mathrm{CN}}$ is determined from simultaneous measurements. A modification of this parameterization was proposed recently by DeMott et al. (2010).

Several heterogeneous ice nucleation parameterizations have been suggested based upon theoretical arguments. These parameterizations included analytical fits to the parcel models simulations and various approximations in the basic equations of the crystal growth (e.g., Sassen and Benson, 2000; Khvorostyanov and Curry, 2000, 2005; Lin et al., 2002; Gierens, 2003; Kärcher and Lohmann, 2003; Liu and Penner, 2005; Barahona and Nenes, 2008, 2009). The utility of classical nucleation theory for parameterization of heterogeneous ice nucleation via solution freezing was limited until recently by the lack of any dependence on supersaturation of the critical radius $r_{\mathrm{cr}}$ and energy $\Delta F_{\mathrm{cr}}$ of ice germs and nucleation rates of freezing process as formulated by Thomson (1888), with temperature dependence only (PK97, eq. 938). Khvorostyanov and Curry (2000, 2004a, b, 2005, 2009, hereafter KC00, KC04a, b, KC05, KC09, respectively) extended classical nucleation theory for heterogeneous freezing and derived equations for the critical radius and energy that included dependencies on both $T$ and water saturation ratio $S_{\mathrm{w}}=\rho_{\mathrm{v}} / \rho_{\mathrm{sw}}$ simultaneously (with $\rho_{\mathrm{sw}}$ being the vapor density saturated over water), or on water supersaturation $s_{\mathrm{W}}=\left(\rho_{\mathrm{v}}-\rho_{\mathrm{sw}}\right) / \rho_{\mathrm{sw}}=S_{\mathrm{w}}-1$, generalizing the previous expressions derived for homogeneous ice nucleation theory by Khvorostyanov and Sassen (1998).

The key parameter in classical nucleation theory is the critical radius $r_{\mathrm{cr}}$ of an ice germ. The equation for $r_{\mathrm{cr}}$ at freezing of a solution drop was derived in $\mathrm{KCO0}, \mathrm{KC} 04 \mathrm{a}, \mathrm{b}$ in the form:

$$
r_{\mathrm{cr}}\left(T, S_{\mathrm{W}}, \varepsilon, r_{\mathrm{a}}, \Delta p\right)=\frac{2 \sigma_{\mathrm{is}}}{\rho_{\mathrm{i}} L_{\mathrm{m}}^{\mathrm{ef}}(T)\left[\ln \left(\frac{T_{0}}{T} S_{\mathrm{w}}^{\mathrm{G}}\right)-H_{\mathrm{v}, \mathrm{fr}}\right]} .
$$

Here $\sigma_{\text {is }}$ is the surface tension at the ice-solution interface, $\rho_{\mathrm{i}}$ is the ice density, $T$ is the temperature in degrees 
Kelvin, $T_{0}=273.15, L_{\mathrm{m}}^{\mathrm{ef}}$ is the effective melting heat (constructed to $-70^{\circ} \mathrm{C}$ in $\left.\mathrm{KC} 09\right), S_{\mathrm{w}}$ is the water saturation ratio, $G=R T /\left(M_{\mathrm{w}} L_{\mathrm{m}}^{\mathrm{ef}}\right), M_{\mathrm{w}}$ is the molecular weight of water, $R$ is the universal gas constant. A function $H_{\mathrm{v}, \mathrm{fr}}=$ $\frac{r_{\mathrm{sc}}}{r_{\mathrm{a}}}+\frac{C_{\varepsilon} \varepsilon^{2}}{\rho_{\mathrm{i}} L_{\mathrm{m}}^{\mathrm{ef}}}+\frac{\Delta \rho \Delta p}{\rho_{\mathrm{w}} \rho_{\mathrm{i}} L_{\mathrm{m}}^{\text {ef }}}$ describes the effects of the misfit strain $\varepsilon$, finite radius $r_{\mathrm{a}}$ of a haze drop, $\Delta \rho=\rho_{\mathrm{w}}-\rho_{\mathrm{i}}, \rho_{\mathrm{W}}$ is the water density, $\Delta p=p-p_{0}$ is the excess pressure, $p_{0}$ is the reference pressure $(1 \mathrm{~atm}), C_{\varepsilon} \sim 1.7 \times 10^{11} \mathrm{dyn} \mathrm{cm}^{-2}$ is the Turnbull-Vonnegut parameter, $p$ is the external applied pressure, $r_{\mathrm{sc}}=2 \sigma_{\mathrm{sa}} /\left(\rho_{\mathrm{i}} L_{\mathrm{m}}^{\mathrm{ef}}\right)$ is the curvature parameter and the term $r_{\mathrm{sc}} / r_{\mathrm{a}}$ describes the effects of curvature of a haze drop on ice nucleation, where $\sigma_{\mathrm{sa}}$ is the surface tension at the solution drop-air interface (KC00, KC04a, b; KC09). KC04a, b described in detail how Eq. (4a) generalizes the previous formulations of the classical nucleation theory and converts into particular cases for specific values of the parameters: $S_{\mathrm{W}}=1$, $T \rightarrow T_{0}, \varepsilon=0, r_{\mathrm{a}} \gg r_{\mathrm{cr}}, \Delta p=0$.

Equation (4a) can be rewritten in another form via the difference between the chemical potential of the metastable phase (solution) $\mu_{\mathrm{mstab}}$ and of the stable phase (ice germ) $\mu_{\text {stab }}$ (Landau and Lifshitz, 1980; Dufour and Defay, 1963)

$r_{\mathrm{cr}}\left(T, S_{\mathrm{w}}, \varepsilon, r_{\mathrm{a}}, \Delta p\right)=\frac{2 \sigma_{\mathrm{is}} v_{\mathrm{i}}}{\mu_{\mathrm{mstab}}-\mu_{\mathrm{stab}}}$,

where $v_{\mathrm{i}}=M_{\mathrm{w}} / \rho_{\mathrm{i}}$ is the molar volume of ice. The difference of molar chemical potentials $\Delta \mu=\mu_{\text {mstab }}-\mu_{\text {stab }}$ is called sometimes "affinity" in meteorological applications (Dufour and Defay, 1963), or "supersaturation" in nonmeteorological literature (Kashchiev, 2000) and plays an important role in thermodynamical analysis of nucleation. Comparison of Eq. (4a) and (4b) allows an expression for affinity using the $\mathrm{KCO0-04} \mathrm{model,} \mathrm{as} \mathrm{a} \mathrm{function} \mathrm{simultane-}$ ously of $T, S_{\mathrm{w}}, \varepsilon, r_{\mathrm{a}}$, and $\Delta p$ :

$\mu_{\mathrm{mstab}}-\mu_{\mathrm{stab}}=M_{\mathrm{w}} L_{\mathrm{m}}^{\mathrm{ef}}(T)\left[\ln \left(\frac{T_{0}}{T} S_{\mathrm{w}}^{\mathrm{G}}\right)-H_{\mathrm{v}, \mathrm{fr}}\right]$,

The phase transition is thermodynamically possible from the metastable phase with higher $\mu_{\text {mstab }}$ to the stable phase with lower $\mu_{\text {stab }}$, when the affinity $\Delta \mu>0$, and Eq. (4c) quantifies this condition in general form. Equation (4a) shows that this condition on affinity is equivalent to the physical condition $r_{\mathrm{cr}}>0$.

The critical energy $\Delta F_{\mathrm{cr}}$ of a germ formation is (Fletcher, 1969; PK97; Curry and Webster, 1999):

$\Delta F_{\mathrm{cr}}\left(T, S_{\mathrm{W}}\right)=\frac{4}{3} \pi \sigma_{\mathrm{is}} r_{\mathrm{cr}}^{2} f\left(m_{\mathrm{is}}, x\right)-\alpha r_{\mathrm{N}}^{2} \sigma_{\mathrm{is}}\left(1-m_{\mathrm{is}}\right)$,

where $m_{\text {is }}$ is the contact or wettability parameter, $x=r_{\mathrm{a}} / r_{\mathrm{cr}}$, and $\alpha$ is the relative area of "active sites" (Fletcher, 1969). A new expression for $\Delta F_{\text {cr }}$ with simultaneous dependence on $T$ and $S_{\mathrm{w}}$ was derived in $\mathrm{KC00}, \mathrm{KC} 04 \mathrm{a}$, b from Eq. (5) with account for Eq. (4a)

$\Delta F_{\mathrm{cr}}=\frac{16 \pi \sigma_{\mathrm{is}}^{3} f\left(m_{\mathrm{is}}, x\right)}{3\left\{\rho_{\mathrm{i}} L_{\mathrm{m}}^{\mathrm{ef}}(T)\left[\ln \left(\frac{T_{0}}{T} S_{\mathrm{w}}^{\mathrm{G}}\right)-H_{\mathrm{v}, \mathrm{fr}}\right]\right\}^{2}}-\alpha r_{\mathrm{N}}^{2} \sigma_{\mathrm{is}}\left(1-m_{\mathrm{is}}\right),(6 \mathrm{a})$ which is used in the $\mathrm{KC}$ scheme. With $\alpha=0$ and $H_{\mathrm{v}, \mathrm{fr}}=0$, Eq. (6a) is simplified (KC00, KC04a)

$$
\Delta F_{\mathrm{cr}}=\frac{16 \pi \sigma_{\mathrm{is}}^{3} f\left(m_{\mathrm{is}}, x\right)}{3\left[\rho_{\mathrm{i}} L_{\mathrm{m}}^{\mathrm{ef}}(T) \ln \left(\frac{T_{0}}{T}\right)+\frac{\rho_{\mathrm{i}} R T}{M_{\mathrm{w}}} \ln S_{\mathrm{w}}\right]^{2}} .
$$

The nucleation rates $J_{\text {het }}$ in classical nucleation theory are evaluated as (Fletcher, 1962; Dufour and Defay, 1963; PK97; Seinfeld and Pandis, 1998; Kashchiev, 2000)

$J_{\text {het }}=\frac{k T}{h} N_{\text {mon }} Z_{\mathrm{s}} \Omega_{\mathrm{s}} c_{1 \mathrm{~s}} 4 \pi r_{\mathrm{N}}^{2} \exp \left(-\frac{\Delta F_{\mathrm{act}}+\Delta F_{\mathrm{cr}}}{k T}\right)$,

where $\Delta F_{\text {act }}$ is the activation energy, $k$ and $h$ are the Boltzmann's and Planck's constants, $c_{1 \mathrm{~s}}$ is the concentration of water molecules adsorbed on $1 \mathrm{~cm}^{2}$ of a surface, $r_{\mathrm{N}}$ is the radius of insoluble substrate, $N_{\text {mon }}$ is a number of monomers of water in contact with unit area of ice surface, $\Omega_{\mathrm{s}}$ is the surface area of the germ, and $Z_{\mathrm{s}}$ is the Zeldovich (1942) factor refined for heterogeneous nucleation in Vehkamäki et al. (2007). The parameters in Eqs. (4a)-(7) are taken mostly from PK97 with some modifications described in $\mathrm{KC} 04 \mathrm{~b}$, $\mathrm{KC} 05, \mathrm{KC} 09$. A new temperature dependent model of the active sites area $\alpha(T)$ is developed here, tested and described below.

The total number of particles nucleated in DHetF mode (IN concentration) is obtained in the $\mathrm{KC}$ scheme by integrating over the superposition of the size spectra of several IN species, which is a subset of aerosol populations that possess ice nucleating ability:

$N_{\mathrm{c}}(t)=\sum_{i=1}^{k} \int_{r_{\min }}^{r_{\mathrm{max}}} P_{\mathrm{fr}}\left(r_{\mathrm{a}}, r_{\mathrm{N}}, t\right) f_{\mathrm{ai}}\left(r_{\mathrm{a}}\right) d r_{\mathrm{a}}$,

where $f_{\mathrm{ai}}\left(r_{\mathrm{a}}\right)$ is the size spectrum of the $i$-th fraction of total $k$ IN fractions, each of which has specific properties (contact parameter $m_{\mathrm{i}}$, active sites area $\alpha_{\mathrm{i}}$, mean radius $r_{\mathrm{i}}$, etc.), and is normalized to the concentration $N_{\text {ai }}$

$N_{\mathrm{ai}}(t)=\int_{r_{\min }}^{r_{\max }} f_{\mathrm{ai}}\left(r_{\mathrm{a}}\right) d r_{\mathrm{a}}$

$P_{\mathrm{fr}}\left(r_{\mathrm{a}}, r_{\mathrm{N}}, t\right)=1-\exp \left(-\int_{0}^{t} J_{\text {het }}\left(r_{\mathrm{a}}, r_{\mathrm{N}}, t^{\prime}\right) d t^{\prime}\right)$ is the probability of freezing at a time $t$ of a single deliquescent IN particle or drop with radius $r_{\mathrm{a}}$ containing an insoluble substrate with radius $r_{\mathrm{N}}$ and depending also on $m_{\mathrm{i}}, \alpha_{\mathrm{i}}$, and other properties of that particle.

The crystal nucleation rate $R_{\mathrm{fr}}\left(\mathrm{cm}^{-3} \mathrm{~s}^{-1}\right)$ in a polydisperse aerosol can be calculated as:

$R_{\mathrm{fr}}=\frac{d N_{\mathrm{fr}}}{d t}=\sum_{i=1}^{k} \int_{r_{\mathrm{min}}}^{r_{\mathrm{max}}} d r_{\mathrm{N}} f_{\mathrm{ai}}\left(r_{\mathrm{a}}\right) J_{\mathrm{s}, \mathrm{fr}}(t) \exp \left(-\int_{0}^{t} J_{\mathrm{s}, \mathrm{fr}}\left(t^{\prime}\right) d t^{\prime}\right)$.

Various aerosol species can serve as IN (PK97): mineral particles (e.g., kaolinite, montmorillonite, dust), soot of various 
origin, biological particles (bacteria, pollen, leaf litter) that have especially high nucleation temperature thresholds of -4 to $-7{ }^{\circ} \mathrm{C}$ (e.g., Diehl and Wurzler, 2004; Chen et al., 2008). A superposition of the size spectra of all of these species can be substituted into Eqs. (8a), (9), and each IN species would give a corresponding contribution to the nucleation. The number $k$ of IN species can be 1-3-6 or greater, e.g., Diehl and Wurzler (2004), and Chen et al. (2008) analyze and present parameters for more than 20 IN species, that can be specified based on the IN properties measured in some experiment. If such detailed measurements are absent, the choice of IN spectra $f_{\mathrm{ai}}\left(r_{\mathrm{a}}\right)$ and $N_{\mathrm{ai}}$ can be based on the plausible hypotheses that integrate previous measurements and theory. If measured IN size spectra are not available, they can be approximated as lognormal or equivalently as algebraic spectra (following Khvorostyanov and Curry, 2006, 2007).

It should be emphasized that the concentrations $N_{\mathrm{ai}}$ of IN species used in the classical theory, in particular, in $\mathrm{KC}$ ice scheme, can be substantially smaller than the total aerosol concentration $N_{\mathrm{a} \text {,tot }}$ (as is the case with concentrations of cloud condensation nuclei, $\mathrm{CCN}$ ), since only a relatively small fraction of total aerosol possesses necessary nucleating properties (e.g., PK97). The IN concentrations $N_{\text {IN, exp }}$ measured with experimental devices are typically $\sim 1-201^{-1}$, rarely exceeding $1001^{-1}$ (see Sect. 4). We expect that $N_{\text {IN, exp }}$ should be smaller than concentrations $N_{\mathrm{ai}}$ used in Eqs. (8a, b), (9) that may potentially serve as IN, since any device can measure only a fraction of $N_{\text {ai }}$ due to various experimental limitations.

It has been already emphasized in MDC92 that measurements with filters and other devices prior to use of CFDC provided IN concentrations at least an order of magnitude smaller than those measured by more powerful devices like CFDC. The CFDCs also likely provide a lower limit of IN, and probably the next generations of improved instruments will yield higher values of $N_{\mathrm{IN} \text {,exp }}$. Numerical experiments with parcel and other models and the $\mathrm{KC}$ scheme also show that concentrations of nucleated ice crystals $N_{\mathrm{c}}$ are smaller than the input concentration $N_{\mathrm{ai}}$ and depends on the cooling rate and process duration (Khvorostyanov et al., 2003; KC05, EDK09). A general characteristic relation among all these concentrations can be outlined as

$N_{\mathrm{IN}, \exp }<N_{\mathrm{c}} \leq N_{\mathrm{ai}}<N_{\mathrm{a}, \text { tot }}$.

These relations are discussed also in Sect. 4.

The system of Eqs. (4a)-(9) comprise the essence of the $\mathrm{KC}$ heterogeneous ice nucleation scheme with simultaneous account for the dependence on temperature, humidity, misfit strain, finite size of freezing particles and external pressure that was used in $\mathrm{KC} 00-\mathrm{KC} 09$ to describe critical radii and energies, kinetics, thresholds and other properties of heterogeneous ice nucleation. Equations (4a)-(9) show that the input information may include complete data for individual aerosol particles obtained in experiments: concentrations and size spectra, contact angle or wettability parameter, activation energy $\Delta F_{\text {act }}$, surface tension, active site area. Hence the KC ice nucleation scheme enables determination of aerosol specific properties and differences in their nucleation abilities.

Liu and Penner (2005) used a particular case of $\Delta F_{\mathrm{cr}}$ from KC00, Eq. (6b) here, with $H_{\mathrm{v}, \text { fr }}=0$ and $\alpha=0$, i.e., without account for misfit strain, the finite radius of a haze drop and without active sites (eq. 2.6 in Liu and Penner) to develop an ice nucleation parameterization for a GCM (Liu et al., 2007). EDK09 used a more detailed version of Eq. (4a), for $r_{\text {cr }}$ and Eq. (6a) for $\Delta F_{\text {cr }}$ for a comparison of the KC and PDA08 schemes, althought with values $N_{\mathrm{ai}}=10001^{-1}$ that are 2-3 orders of magnitude higher than typical values in CFDC.

Chen et al. (2008) refined calculations of nucleation rates in the classical nucleation theory by fitting its parameters $\left(\Delta F_{\text {act }}, m_{\mathrm{is}}\right)$ based on laboratory measurements of ice nucleation on IN of various origins (soot, bacteria, pollen, and dust). It was shown that the contact parameters of several substances can be very close to unity, which may explain the high temperature threshold of ice nucleation when such substances are present. Most of the results in Chen et al. (2008) were related to the deposition mode; a possible extension to the freezing mode and account for the solute freezing depression were briefly outlined.

In this paper, we analyze several empirical parameterizations and compare them with the KC theoretical approach based on the classical nucleation theory. In Sect. 2, thermodynamic constraints on heterogeneous ice nucleation are examined. In Sect. 3, an empirical parameterization by Phillips et al. (2008; hereafter PDA08) is compared with the theoretical $\mathrm{KC}$ ice scheme in parcel model simulations in evaluation with the climatological data and GCMs parameterizations of cloud phase state. Section 4 compares the results of numerous parcel runs with $\mathrm{KC}$ ice nucleation scheme to the results of ice nuclei measurements in the six recent field campaigns and some laboratory measurements. In Sect. 5, the low-level mixed-phase arctic cloud observed during MPACE is simulated using a 1-D model with spectral bin microphysics and it is shown that the $\mathrm{KC}$ ice scheme reproduces the correct quasi-state mixed phase of this cloud for a few hours.

\section{Thermodynamic constraints on heterogeneous ice nucleation schemes}

Heterogeneous nucleation schemes that depend on temperature and/or supersaturation have been derived from both empirical and theoretical bases. Here we assess the range of validity of these parameterizations in the context of thermodynamic constraints derived from the extended classical nucleation theory described by $\mathrm{KC}$.

The critical radius $r_{\text {cr }}$ of an ice germ in Eq. (4a) is positive if the denominator is positive, yielding a condition for the threshold $S_{\mathrm{w}, \mathrm{th}}(T)$ or $T_{\mathrm{th}}\left(S_{\mathrm{w}}\right)$ for ice particle nucleation (KC04a, b, KC09): 


$$
\begin{aligned}
& S_{\mathrm{w}, \mathrm{th}}(T)=\left(\frac{T}{T_{0}}\right)^{M_{\mathrm{w}} L_{\mathrm{m}}^{\mathrm{ef}} / R T} \exp \left[\frac{M_{\mathrm{w}}}{\rho_{\mathrm{i}} R T}\left(C_{\varepsilon} \varepsilon^{2}+\frac{2 \sigma_{\mathrm{sa}}}{r_{\mathrm{a}}}+\frac{\Delta \rho \Delta p}{\rho_{\mathrm{w}}}\right)\right], \\
& T_{\mathrm{th}}\left(S_{\mathrm{w}}\right)=T_{0} S_{\mathrm{w}}^{R T / M_{\mathrm{w}} L_{\mathrm{m}}^{\mathrm{ef}}} \exp \left(-\frac{C_{\varepsilon} \varepsilon^{2}}{\rho_{\mathrm{i}} L_{\mathrm{m}}^{\mathrm{ef}}}-\frac{r_{\mathrm{sc}}}{r_{\mathrm{a}}}-\frac{\Delta \rho \Delta p}{\rho_{\mathrm{w}} \rho_{\mathrm{i}} L_{\mathrm{m}}^{\mathrm{ef}}}\right) .
\end{aligned}
$$

The notations were defined following Eq. (4a). Equations (11a), (11b) represent a lower and upper limits for $S_{\mathrm{w}}$ and $T$ respectively for infinitesimally small nucleation rates $J_{\text {het }}$, the more general equations for finite $J_{\text {het }}$ are given in $\mathrm{KC0} 4 \mathrm{a}, \mathrm{b}, \mathrm{KC09}$, they predict somewhat higher $S_{\mathrm{w}, \text { th }}$ and lower $T_{\text {th }}$ that depend on $J_{\text {het }}$; the latter is in qualitative agreement with Kashchiev et al. (2010). The condition (11a) is similar to the parameterizations of the threshold humidity for homogeneous nucleation (e.g., Sassen and Dodd, 1989; Heymsfield and Sabin, 1989), but predicts substantially lower $S_{\mathrm{w}, \text { th }}$ for heterogeneous nucleation (KC09).

Equations (4a) and (11a), and (11b) show that the value $r_{\mathrm{cr}}>0$ if $S_{\mathrm{w}}>S_{\mathrm{w}, \text { th }}$ at given $T$ or if $T<T_{\mathrm{th}}$ at given $S_{\mathrm{w}}$, and only these states are thermodynamically allowed in the $S_{\mathrm{W}}-$ $T$ domain. The denominator of the critical radii $r_{\mathrm{cr}}$ of ice germs in Eq. (4a) (affinity $\Delta \mu$ ) becomes negative and $r_{\mathrm{cr}}<0$ in the $S_{\mathrm{w}}-T$ domain if $S_{\mathrm{w}}<S_{\mathrm{w} \text {, th }}$ at given $T$, i.e., where the relative humidity over water (RHW) is smaller than its threshold value, $\delta\left(\mathrm{RHW}_{\mathrm{th}}\right)=\mathrm{RHW}-\mathrm{RHW}_{\mathrm{th}}=\left(S_{\mathrm{W}}-\right.$ $\left.S_{\mathrm{W}, \text { th }}\right) \cdot 100 \%<0$, or where $T>T_{\text {th }}$ at given $S_{\mathrm{W}}$ (see also $\mathrm{KC04b}, \mathrm{KC} 09$ ). As pointed out above, the condition $r_{\mathrm{cr}}>0$ means that if $\mu_{\text {mstab }}>\mu_{\text {stab }}$ (affinity $\Delta \mu>0$ ), then such a transition is thermodynamically allowed. The reverse condition $r_{\mathrm{cr}}<0$ or $\Delta \mu<0$ means that the transition is prohibited from the state with lower energy $\mu_{\text {stab }}$ to the state with higher energy $\mu_{\mathrm{mstab}}$.

Note that Eqs. (4a) to (11b) are based on the classical nucleation theory with use of the capillary approximation and the concept of "surface". These approximations and concepts become invalid near $r_{\mathrm{cr}}=0$, when the number of molecules in a germ is too small. As discussed in detail in Dufour and Defay (1963) and Defay et al. (1966), this limitation is pertinent to the very small area around $r_{\mathrm{cr}}=0$, a narrow belt in $T-S_{\mathrm{w}}$ plane (Fig. 1). This imposes a small uncertainty on the line $r_{\mathrm{cr}}\left(T, S_{\mathrm{w}}\right)=0$ but does not influence the general validity of the above conditions and conclusions since the major area with $r_{\mathrm{cr}}<0$ and $\Delta \mu<0$ lies well above the line $r_{\mathrm{cr}}=0$ and is free of limitations for the capillary approximations. Another note is that the constraints (11a), (11b) are sufficiently general, and do not contain any information on aerosol size spectra and contact parameters; they follow from the entropy equation used for derivation of $r_{\mathrm{cr}}$ in Eq. (4a) that is based on classical thermodynamics.

Here we assess the range of thermodynamic validity of the MC92, DM98, and PDA08 ice nucleation parameterization schemes on the $S_{\mathrm{W}}-T$ diagrams using values of $N_{\mathrm{c}}$ calculated with parameterizations MC92 (Eq. 1 here), and DM98 (Eq. 3 here and $N_{\mathrm{CN}} \sim 200 \mathrm{~cm}^{-3}$ as in fig. 1 in DM98). Calculations were performed over a wide range of values of $s_{\mathrm{i}}$ and $T$. For comparison with $S_{\mathrm{w}, \text { th }}$ and $\delta\left(\mathrm{RHW}_{\mathrm{th}}\right)$, these quantities were calculated for pairs of $S_{\mathrm{i}}$ and $T$ values. Calculated values of $N_{\mathrm{c}}\left(S_{\mathrm{i}}\right)$ and $N_{\mathrm{c}}(T)$ were superimposed on the field of $\delta\left(\mathrm{RHW}_{\text {th }}\right)$ in Fig. 1 in $S_{\mathrm{w}}-T$ coordinates calculated using Eq. (11a).

Figure 1 represents an $S_{\mathrm{w}}-T$ diagram over the domain $-30<T<0{ }^{\circ} \mathrm{C}$ and $0.7<S_{\mathrm{W}}<1.0$. Superimposed here is the threshold difference $\delta\left(\mathrm{RHW}_{\mathrm{th}}\right)$, whereby the deep blue hatched line denotes the boundary RHW $=\mathrm{RHW}_{\text {th }}$ or $r_{\mathrm{cr}}(T$, $S_{\mathrm{W}}$ ) $=0$ (excluding the very narrow strip around this line due to limitations of capillary approximation discussed above). The states above this line (white field) correspond to negative values of $r_{\mathrm{cr}}$ and negative difference $\Delta \mu$ of chemical potentials, $\mu_{\text {ustab }}<\mu_{\text {stab }}$. That is, ice germs cannot be nucleated above this line in this $S_{\mathrm{W}}-T$ area, which corresponds to the reverse transition from the stable to metastable phase and is thermodynamically prohibited. Only the states with $r_{\mathrm{cr}}>0$ or $\Delta \mu>0$ below the blue hatched line RHW $-\mathrm{RHW}_{\text {th }}=0$ (shaded field) are thermodynamically allowed for heterogeneous ice nucleation by freezing. Figure 1 shows that the allowed $T-S_{\mathrm{w}}$ domain is located in the triangle below temperature of -8 to $-12{ }^{\circ} \mathrm{C}$ and at water saturation ratio above 0.8 to 0.83 , this area covering only about $1 / 8$ of the entire domain considered. We note here that ice nucleation in the MDC92 and DM98 schemes (as in DeMott et al., 2010) is allowed in the thermodynamically prohibited region. The boundaries of the allowed domain depend of the size $r_{\mathrm{a}}$ of aerosol particles. When $r_{\mathrm{a}}$ increases from $0.05 \mu \mathrm{m}$, typical of the fine mode, to $1 \mu \mathrm{m}$ typical of the coarser mode, the allowed domain shifts to higher temperatures by about $5^{\circ} \mathrm{C}$ allowing ice nucleation at warmer temperatures.

It is interesting to note that the isolines of the MDC92 $s_{\mathrm{i}}$-parameterization are in good correlation (almost parallel) with the isolines of $\delta\left(\mathrm{RHW}_{\mathrm{th}}\right)$. Thus, both MDC92 empirical scheme and $\mathrm{KC}$ theoretical scheme produce similar dependencies indicating that both schemes capture some basic physical features of the nucleation process. However, the gradients $d N_{\mathrm{c}} / d S_{\mathrm{w}}$ and $d N_{\mathrm{c}} / d T$ in MDC92 are noticeably smaller than predicted by the classical theory. This may be caused by averaging over aerosols with different properties in CFDC experiments (MDC92 scheme), while calculations with $\mathrm{KC}$ scheme included here only a single aerosol type. The agreement of DM98 $T$-parameterization (and of similar DeMott et al., 2010) with classical theory is somewhat worse because they do not account for the humidity dependence.

We do not present here similar thermodynamic analysis of the other existing parameterizations but this is easily done for any function $N_{\mathrm{c}}(T)$ and $N_{\mathrm{c}}\left(s_{\mathrm{i}}\right)$. These thermodynamic limitations also should be accounted for when choosing and comparing the empirical and theoretical parameterizations of ice nucleation in the numerical models of various complexity as e.g., in Comstock et al. (2008) and Eidhammer et al. (2009), and empirical parameterizations should not be applied outside of thermodynamically allowed conditions. 

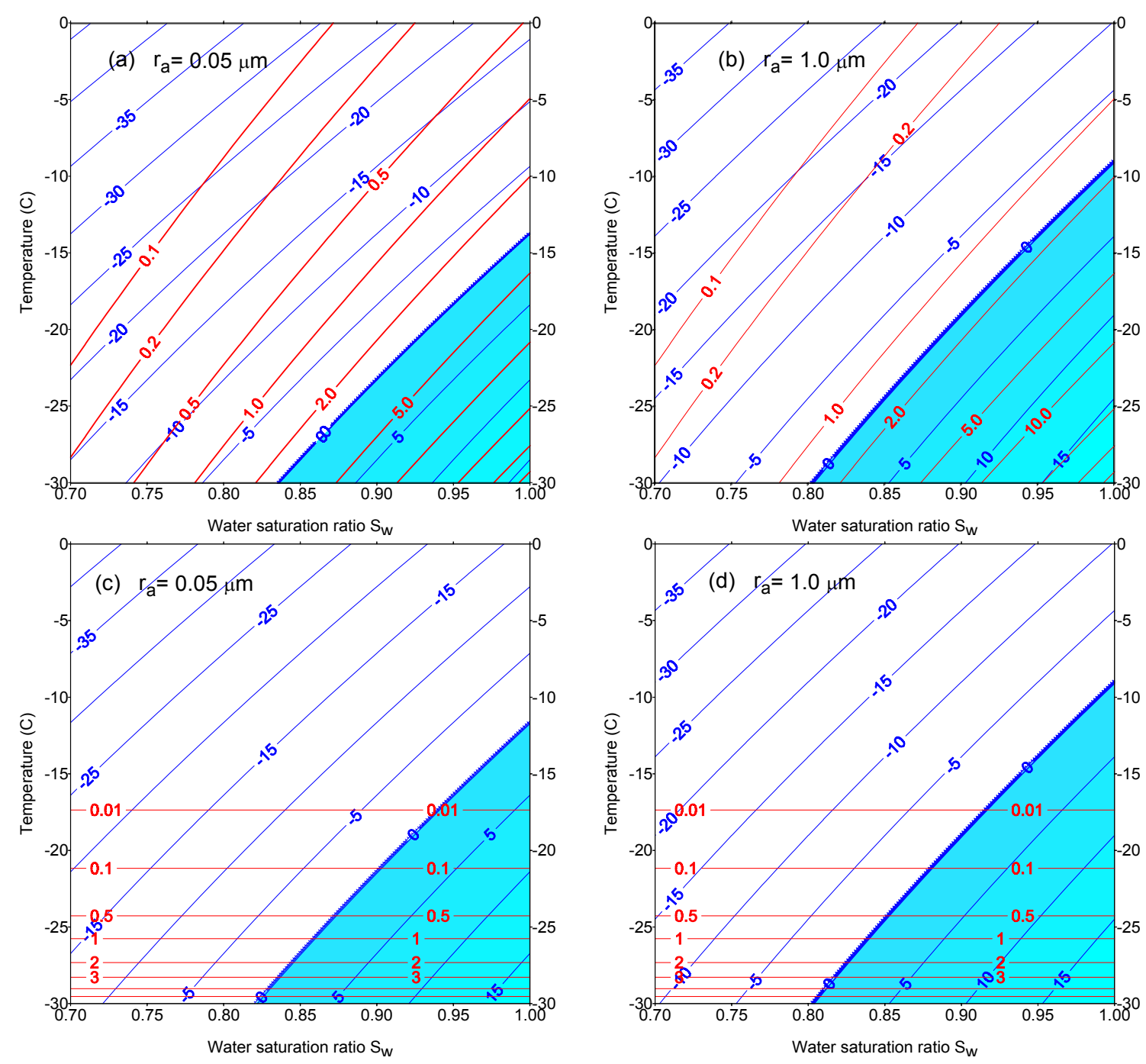

Fig. 1. $S_{\mathrm{W}}-T$ diagrams of $N_{\mathrm{c}}$ calculated with MDC92 (a, b), Eq. (1) here, and DM98 (c, d), Eq. (3) here, parameterizations (red lines and labels) with superimposed threshold difference $\delta\left(\mathrm{RHW}_{\mathrm{th}}\right)=\mathrm{RHW}-\mathrm{RHW}_{\mathrm{th}}=\left(S_{\mathrm{W}}-S_{\mathrm{W}, \mathrm{th}}\right) \cdot 100 \%$ (blue lines and labels) calculated from Eq. (11a) as in KC09. The line $\delta\left(\mathrm{RHW}_{\mathrm{th}}\right)=0$ or RHW $=\mathrm{RHW}_{\text {th }}$ is indicated by deep blue and hatched. The physical states and $N_{\mathrm{c}}$ above this line (white) are below the critical humidity, $S_{\mathrm{i}}<S_{\mathrm{i}, \mathrm{cr}}$, and blue isolines denote negative deficit $\delta\left(\mathrm{RHW}_{\mathrm{th}}\right)$. These states are thermodynamically prohibited and correspond to the negative critical radii, $r_{\mathrm{cr}}<0$ and negative (reverse) difference $\Delta \mu$ of chemical potentials, $\mu_{\mathrm{ustab}}<\mu_{\mathrm{stab}}$. Only the states below the blue hatched line $\mathrm{RHW}-\mathrm{RHW}_{\mathrm{th}}=0$ (blue filled field) correspond to $r_{\mathrm{cr}}>0, \Delta \mu>0$ and are thermodynamically allowed.

\section{Evaluation of phase state simulations}

Eidhammer et al. (2009, hereafter EDK09) compared three parameterizations of heterogeneous ice nucleation using a parcel model developed at Colorado State University (CSU). The model is based on the spectral bin microphysics for the mixed and ice states with various parameterizations of ice nucleation. The three ice nucleation schemes included PDA08, $\mathrm{KC}$, and DW04. Comparing the results of simulations for the three parameterizations, EDK09 found that for small vertical velocities $w \sim 5 \mathrm{~cm} \mathrm{~s}^{-1}$, all three parameterizations yield similar results. For large $w$, only PDA08 compares well with typical observations of ice nucleation in CFDC producing $N_{\mathrm{c}}$ $\sim 1-201^{-1}$, while the other two parameterizations (DW04 and $\mathrm{KC}$ ) produce crystal concentrations much higher than PDA08. EDK09 recommend that the empirically-derived "constraint" on the upper limit of $N_{\mathrm{c}}$ used in the PDA08 scheme should be used in cloud and climate models parameterizations.

In this section, the PDA08 and KC schemes are compared further to understand the sources of the discrepancies between the two parameterizations (we note that the DW04 scheme performs comparably to $\mathrm{KC}$ and produces comparable values of $N_{\mathrm{c}}$ ). We carry out simulations using the parcel model described in $\mathrm{KC} 05$. The drop 
nucleation parameterization was substantially modified according to Khvorostyanov and Curry (2006, 2007, hereafter $\mathrm{KC} 06, \mathrm{KC07})$, where a generalized power law $N_{\mathrm{d}}\left(s_{\mathrm{W}}\right)=$ $C\left(s_{\mathrm{w}}\right) s_{\mathrm{w}}^{k\left(s_{\mathrm{w}}\right)}$ was derived. Both $C$ and $k$ depend on water supersaturation $s_{\mathrm{W}}$ and decrease with increasing $s_{\mathrm{W}}$, in agreement with the observed experimentally quantities (e.g., Yum and Hudson, 2001), yielding finite $N_{\mathrm{d}}$ limited by $N_{\mathrm{a}}$ at high $s_{\mathrm{W}}$. We used the same composition of aerosol as in EDK09, and the KC heterogeneous DHetF ice nucleation scheme. Simulations are conducted with the active site area $\alpha$ in Eq. (6a) in two forms: $\alpha=0$; and a new parameterization of $\alpha$ as a function of $T$,

$\alpha(T)=\alpha_{0}\left(1-T_{\mathrm{c}} / T_{\mathrm{v}}\right) \theta\left(T_{\mathrm{th}}-T_{\mathrm{c}}\right) \theta\left(T_{\mathrm{c}}-T_{\mathrm{v}}\right)$,

where $\alpha_{0}=2 \times 10^{-5}$ was successfully tested in $\mathrm{KC} 05$ for explanation of fast glaciation of polar maritime cumulus observed in Hobbs and Rangno (1990), Rangno and Hobbs (1991) without high water supersaturation. $\theta(x)$ is the Heaviside function, $T_{\mathrm{th}}=-5^{\circ} \mathrm{C}$ is the threshold temperature of nucleation close to that assumed in EDK09, and $T_{\mathrm{v}}=-20^{\circ} \mathrm{C}$ is the scaling temperature that determines the rate of decrease of $\alpha(T)$. Equation (12) indicates that $\alpha(T)$ has a maximum $\alpha_{0}=2 \times 10^{-5}$ at warm $T$, decreases to 0 at $T_{\mathrm{v}}=-20^{\circ} \mathrm{C}$, and $\alpha(T)=0$ at $T_{\mathrm{c}}<T_{\mathrm{v}}$. This parameterization accounts for the fact that the area of the sites close to the structure of water $\left(m_{\mathrm{is}}=1\right)$ that are favorable for nucleation increases toward $0^{\circ} \mathrm{C}$. We hypothesize that these sites can be formed by crystal defects, steps, or premelted sites. Their exact origin does not matter for now, but it is known that the number of such sites may increase toward $0^{\circ} \mathrm{C}$ (Hobbs, 1974; Dash et al., 1995).

Simulations were conducted under the following conditions: $w=50 \mathrm{~cm} \mathrm{~s}^{-1}, \mathrm{RHW}_{0}=96 \%, T_{0}=10^{\circ} \mathrm{C}$. The $\mathrm{KC}$ scheme was used with DHetF mode in 3 versions. The input data for these 3 runs are given in Table 1: (\#1) only one coarse aerosol fraction included as in EDK09, lognormal size spectrum, concentration $N_{\mathrm{IN}, 2}=1 \mathrm{~cm}^{-3}\left(1000 \mathrm{l}^{-1}\right)$, mean geometric radius $r_{\mathrm{d} 2}=0.4 \mu \mathrm{m}$, dispersion $\sigma_{\mathrm{d} 2}=2$, and active site area $\alpha=0$; (\#2) the same coarse aerosol fraction, $N_{\mathrm{IN}, 2}=1 \mathrm{~cm}^{-3}$, but variable $\alpha(T)$ described by Eq. (12); (\#3) $\alpha=0$, and including 3 IN lognormal fractions with equal concentrations $N_{\mathrm{IN}, 1}=N_{\mathrm{IN}, 2}=N_{\mathrm{IN}, 3}=101^{-1}$ $\left(=10^{-2} \mathrm{~cm}^{-3}\right.$, i.e., 100 times smaller than in runs \#1 and $\# 2$ and in EDK09 for KC scheme), $r_{\mathrm{d} 1}=r_{\mathrm{d} 2}=r_{\mathrm{d} 3}=0.4 \mu \mathrm{m}$, but 3 different values of contact parameter, $0.85,0.75$ and 0.5 that can mimic a mixture of organic (bacteria or pollen), soot and mineral IN. The IN concentration of $1 \mathrm{~cm}^{-3}$ in the runs \#1 and \#2 follows the choice in EDK09 for the KC scheme, although it is not clear why this very high concentration $N_{\mathrm{IN}, 2}$ was chosen in EDK09. This is an arbitrary choice, 2-3 orders of magnitude higher than typical IN concentrations in CFDC, and it is not related to any characteristic of the KC or DW04 schemes. In run \#3, the concentrations were chosen comparable to those measured in CFDCs and used in PDA08.
Table 1. Parameters of the 3 simulations (runs) of the parcel model with the $\mathrm{KC}$ scheme and various input data.

\begin{tabular}{|c|c|c|}
\hline Run & Model of $\alpha$ & Model of IN microphysics \\
\hline$\# 1$ & 0 & $\begin{array}{l}\text { One fraction with lognormal size } \\
\text { spectrum, concentration } N_{\mathrm{IN}, 2}= \\
1 \mathrm{~cm}^{-3}\left(10001^{-1}\right) \text {, mean geomet- } \\
\text { ric radius } r_{\mathrm{d} 2}=0.4 \mu \mathrm{m} \text {, dispersion } \\
\sigma_{\mathrm{d} 2}=2\end{array}$ \\
\hline \#2 & $\alpha(T)$ by Eq. (12) & $\begin{array}{l}\text { One fraction with lognormal size } \\
\text { spectrum, same as in run } \# 2\end{array}$ \\
\hline \#3 & 0 & $\begin{array}{l}\text { Three IN lognormal frac- } \\
\text { tions with equal concentrations } \\
N_{\mathrm{IN}, 1}=N_{\mathrm{IN}, 2}=N_{\mathrm{IN}, 3}=101^{-1} \\
\left(=10^{-2} \mathrm{~cm}^{-3}\right), r_{\mathrm{d} 1}=r_{\mathrm{d} 2}=r_{\mathrm{d} 3}= \\
0.4 \mu \mathrm{m} \text {, but } 3 \text { different values of } \\
\text { contact parameter, } 0.85,0.75 \text { and } \\
0.5\end{array}$ \\
\hline
\end{tabular}

The results of simulations from EDK09 with ice scheme PDA08 and from the 3 simulations of our parcel model with the KC scheme are compared in Fig. 2. Due to high initial RHW, drop activation occurs in a few minutes (a bit earlier than in EDK09 due to a little higher $\mathrm{RHW}_{0}$, but this is unimportant). The drop concentration $N_{\mathrm{d}}$ is $\sim 90 \mathrm{~cm}^{-3}$ in EDK09 model and $160 \mathrm{~cm}^{-3}$ in $\mathrm{KC}$ model, the difference associated with different drop activation methods. Values of $N_{\mathrm{d}}$ are constant in EDK09 simulations for $4 \mathrm{~h}$ (Fig. 2c), and liquid water content (LWC) increases over this period due to drop growth down to $T=-34.5^{\circ} \mathrm{C}$ (Fig. 2e). In the EDK09 model with PDA08 ice scheme, noticeable heterogeneous crystal nucleation begins at about $75 \mathrm{~min}$ when $T<-3{ }^{\circ} \mathrm{C}$, their concentration $N_{\mathrm{c}}$ increases almost linearly and reaches $\sim 221^{-1}$ at $T \sim-32.5^{\circ} \mathrm{C}$ at a height above $6 \mathrm{~km}$ and time $240 \mathrm{~min}$ (Fig. 2d). Thus, nucleation with PDA08 scheme continues over almost $4 \mathrm{~h}$, much longer than in any other heterogeneous scheme (e.g., Sassen and Benson, 2000; Lin et al., 2002; Kärcher and Lohmann, 2003; KC05; Liu and Penner, 2005), and much longer than in CFDC experiments, only 7-15 s (Phillips et al., 2008). Thus, the nucleation rates in EDK09 simulations with PDA08 scheme are several orders of magnitude smaller than in CFDC experiments upon which PDA08 parameterization is based, and the correspondence between the measurements over a few seconds and their extension for several hours is not clear. Then an abrupt increase in $N_{\mathrm{c}}$ occurs by almost 3 orders of magnitude to $1.6 \times 10^{4} 1^{-1}$ caused by homogeneous drop freezing, which begins in EDK09 model at the heights above $6 \mathrm{~km}$, at $T \approx-34^{\circ} \mathrm{C}$, close to the freezing threshold for the drops with radii of $18-20 \mu \mathrm{m}$. At temperatures warmer than $-34^{\circ} \mathrm{C}$, the nucleated ice crystals do not influence $N_{\mathrm{d}}$ and 

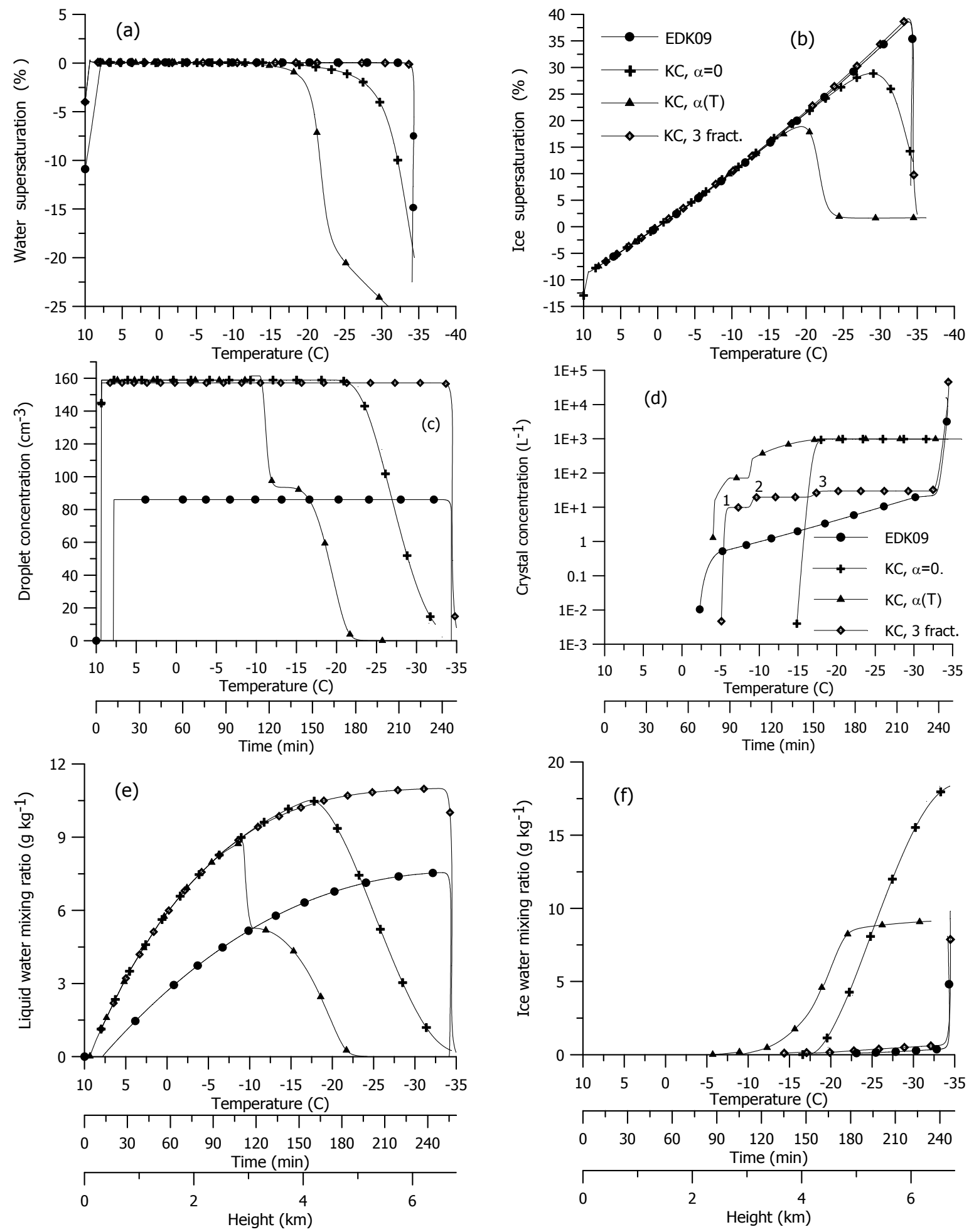

Fig. 2. Comparison of the temperature and time dependencies of cloud microphysical properties in the parcel runs obtained in simulations EDK09 with parameterization PDA08 (solid circles) and obtained in simulations of this work using KC scheme with DHetF mode in 3 simulations (see Table 1): (\#1) only 2nd aerosol mode included as in EDK09, $N_{\mathrm{d} 2}=1 \mathrm{~cm}^{-3}\left(10001^{-1}\right), \sigma_{\mathrm{d} 2}=2, r_{\mathrm{d} 2}=0.4 \mu \mathrm{m}$, and active site area $\alpha=0$ (crosses); (\#2) only the same 2 nd aerosol mode and variable $\alpha(T)$ as described by Eq. (12) (triangles); (\#3) 3 IN fractions included with 3 values of contact parameter, $0.85,0.75$ and 0.5 , and concentrations 10,10 and $101^{-1}$ (diamonds). The 3 nucleation impulses in $N_{\mathrm{c}}$ in the run \#3 are denoted by the numbers (Fig. $2 \mathrm{~d}$ ). The parameters: $w=50 \mathrm{~cm} \mathrm{~s}^{-1}, \mathrm{RHW}_{0}=96 \%, T_{0}=10^{\circ} \mathrm{C}$. 
LWC, and no signs of Bergeron-Findeisen process and crystallization are seen on the EDK09 curves. Only when the temperature falls to $-35^{\circ} \mathrm{C}$, the instantaneous glaciation occurs due to drop homogeneous freezing, $N_{\mathrm{c}}$ rapidly increases by three orders of magnitude, $N_{\mathrm{d}}$ and LWC abruptly drop to zero. Thus, the crystals heterogeneously formed in PDA08 scheme are unable to produce any noticeable crystallization effect down to $-34^{\circ} \mathrm{C}$ and the "constraints" imposed in the PDA08 scheme lead to a substantial underestimation of heterogeneous ice nucleation.

In contrast, crystallization in the $\mathrm{KC}$ scheme in simulations \#1 and \#2 with $N_{\mathrm{IN}, 2}=1 \mathrm{~cm}^{-3}$ occurs much more smoothly with decreasing temperature, in the temperature range of $\sim 20^{\circ} \mathrm{C}$. With $\alpha=0$, crystal nucleation in $\mathrm{KC}$ scheme begins at $-15^{\circ} \mathrm{C}$ and $N_{\mathrm{c}}$ reaches a maximum $\sim 10^{3} 1^{-1}$ within $2^{\circ} \mathrm{C}$. With the smooth function $\alpha(T)$ in simulation $\# 2$, crystal nucleation begins at about $-5^{\circ} \mathrm{C}$, and ends at $-17^{\circ} \mathrm{C}$, more smoothly than with $\alpha=0$. Cloud glaciation with decreasing $N_{\mathrm{d}}$ and $\mathrm{LWC}$ begins at $-15^{\circ} \mathrm{C}$ with $\alpha=0$ (at $-7{ }^{\circ} \mathrm{C}$ with $\alpha(T)$ ) and ends at $-35^{\circ} \mathrm{C}$ with $\alpha=0$ (at $-23^{\circ} \mathrm{C}$ with $\alpha(T)$ ), over the $T$-range of $16-20^{\circ} \mathrm{C}$ and $1 \mathrm{~h}$ in both cases. Note that the DW04 scheme shown in Fig. 1 in EDK09 (not shown here) performs similarly to the KC scheme in runs \#1 and \#2, and produces realistic crystallization and cloud phase state. In simulation \#3 with $3 \mathrm{IN}$ fractions and with the $\mathrm{KC}$ scheme, heterogeneous nucleation occurs in the three temperature ranges, near $-5,-8$ to -9 , and from -15 to $-18^{\circ} \mathrm{C}$, corresponding to nucleation of each of 3 fractions, from highest to lowest contact parameter. Each nucleation impulse produces values of $N_{\mathrm{c}}$ almost equal to the concentration in the corresponding fractions, $\sim 101^{-1}$, and the total is $\sim 301^{-1}$ at $T<-18{ }^{\circ} \mathrm{C}$. Each nucleation impulse is located in a relatively narrow temperature range of 1$3{ }^{\circ} \mathrm{C}$, but the total temperature range of nucleation stretches over $13{ }^{\circ} \mathrm{C}$.

Figure 2 shows that this nucleation picture and final crystal concentration with $\mathrm{KC}$ scheme in simulation \#3 are close to those produced in EDK09 with PDA08 scheme. With this small final $N_{\mathrm{c}}=301^{-1}$, the KC scheme also does not produce glaciation down to the homogeneous freezing threshold of $-34^{\circ} \mathrm{C}$, when rapid drop freeing and cloud crystallization occur. Thus, the conclusion in EDK09 that the KC scheme produces very high crystal concentrations was caused by an arbitrary and unjustified choice of very high $\left(10001^{-1}\right)$ IN concentration in EDK09. The conclusion that nucleation in the $\mathrm{KC}$ scheme occurs in very narrow temperature range was caused by the choice of just one IN fraction with "monodisperse" properties: contact angle, $\alpha$, etc. A more realistic choice of IN produces nucleation with $\mathrm{KC}$ scheme over a wide $T$-interval.

One criteria for validity of ice nucleation parameterization is the cloud phase state. The phase state in clouds is characterized by the ratio of the liquid (LWC) to the total water (LWC + IWC) in mixed phase, $f_{1}=\mathrm{LWC} /(\mathrm{LWC}$ + IWC) $\cdot 100 \%$. Figure 3 shows the observed climatology

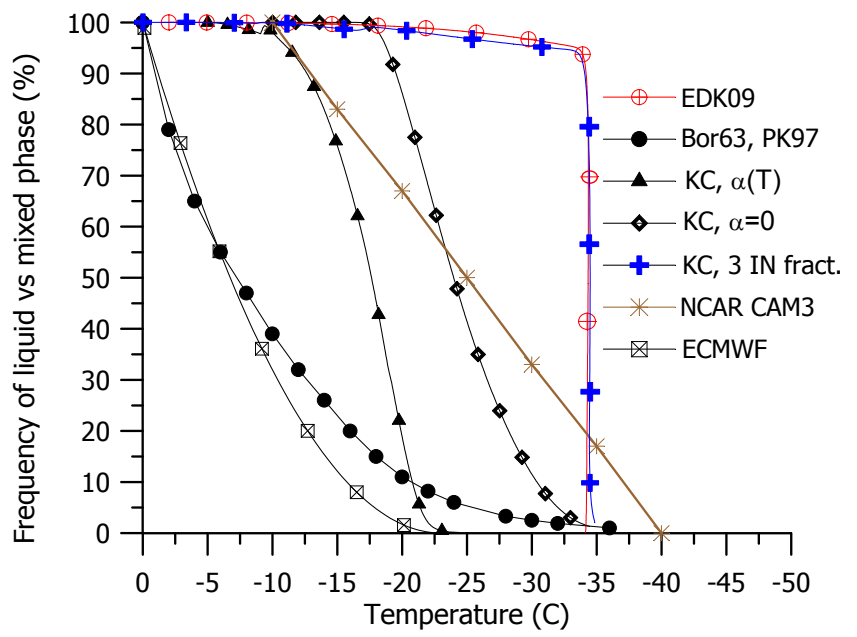

Fig. 3. Frequency of liquid vs. mixed states. Climatological data after Borovikov et al. (1963) (see also figs. 2-33 in PK97), compared to the characteristic of the liquid/mixed phase, the ratio $f_{1}=\mathrm{LWC} /(\mathrm{LWC}+\mathrm{IWC})$, simulated with the KC05-CK10 parcel model and heterogeneous $\mathrm{KC}$ ice scheme in the same 3 simulations shown in Fig. 2 (see Table 1): (\#1) only 2nd aerosol mode included as in EDK09, $N_{\mathrm{d} 2}=1 \mathrm{~cm}^{-3}\left(10001^{-1}\right), \sigma_{\mathrm{d} 2}=2, r_{\mathrm{d} 2}=0.4 \mu \mathrm{m}$, and active site area $\alpha=0$ (diamonds); (\#2) only the same 2nd aerosol mode and $\alpha(T)$ as described in the text (triangles); (\#3) 3 IN fractions included with 3 values of contact parameter, $0.85,0.75$ and 0.5 , and concentrations 10,10 and $101^{-1}$ (blue crosses). These results are compared to EDK09 parcel model simulations with PDA08 ice scheme, the same aerosol and $\alpha=0$ (open red circles), and to the corresponding $T$-partitioning of the liquid and ice phases in the climate models with single-moment microphysics: the NCAR CAM3 (Boville et al., 2006), (83\% liquid at $\left.-15^{\circ} \mathrm{C}\right)$ and ECMWF (ECMWF-2007), $\left(12 \%\right.$ liquid at $-15^{\circ} \mathrm{C}$ ) as described in the text.

of $f_{1}$ compiled of a few thousands aircraft measurements (Borovikov et al., 1963; reproduced in PK97). In pure liquid clouds at warm temperatures slightly below $0{ }^{\circ} \mathrm{C}, f_{1}$ is close to $100 \%$, then decreases with decreasing temperature ( $22 \%$ liquid at $-15^{\circ} \mathrm{C}$ ) and tends to zero at $T<-30^{\circ} \mathrm{C}$, i.e., the clouds become purely crystalline.

Figure 3 compares this climatological data with $f_{1}$ calculated from the simulations data of EDK09 and from the three runs with KC scheme shown in Fig. 2 above comparing two forms of $\alpha(T)$ and two input IN concentrations. These are also compared with the two parameterizations of $f_{1}$ as a function of temperature in two general circulation models: ECMWF (European Centre for Medium-Range Weather Forecasts) and NCAR CAM3 (National Center for Atmospheric Research Community Atmosphere Model 3). In ECMWF, the liquid fraction was chosen as $f_{1}=[(T-$ $\left.\left.T_{\text {ice }}\right) /\left(T_{0}-T_{\text {ice }}\right)\right]^{2}$, and $f_{1}=0$ at $T<T_{\text {ice }}$, with $T_{0}=273.16$ and $T_{\text {ice }}=250.16 \mathrm{~K}\left(12 \%\right.$ liquid at $\left.-15^{\circ} \mathrm{C}\right)$, (ECMWF2007). In NCAR CAM 3 , the ice fraction was parameterized as $f_{\mathrm{i}}(T)=\left(T-T_{\max }\right) /\left(T_{\min }-T_{\max }\right)$ with $T_{\max }=-10{ }^{\circ} \mathrm{C}$, 
$T_{\min }=-40^{\circ} \mathrm{C}$ (Boville et al., 2006); then $f_{1}$ in percent can be written as $f_{1}(T)=1-f_{\mathrm{i}}(T)=\left(T_{\min }-T\right) /\left(T_{\min }-T_{\max }\right)$. 100 , and $f_{1}(T)=0$ at $T<T_{\min }\left(83 \%\right.$ liquid at $\left.-15^{\circ} \mathrm{C}\right)$. Figure 3 shows that the ECMWF parameterization is very close to the climatological data of Borovikov et al. (1963), but ends at slightly warmer temperatures. The CAM3 parameterization has a slope close to the climatological data, but the curve CAM3 is displaced as a whole toward colder temperatures by about $10^{\circ} \mathrm{C}$, underestimating the ice phase at warm and medium temperatures (note that the $T$-limits in NCAR CAM2 were 0 and $-20^{\circ} \mathrm{C}$ (Boville et al., 2006), and $f_{1}(T)$ was closer to the ECMWF).

The $f_{1}(T)$ slopes in the KC scheme in simulations \#1 and $\# 2$ with $N_{\mathrm{IN}, 2}=1 \mathrm{~cm}^{-3}$ are steeper than the climatological, ECMWF and CAM3 values but are still comparable to them, and closer to CAM3. Occurrence of the ice phase increases in $\mathrm{KC}$ scheme at $-16^{\circ} \mathrm{C}$ with $\alpha=0$ and at $-7^{\circ} \mathrm{C}$ with $\alpha(T)$; the threshold with $\alpha(T)$ is close to the threshold in CAM3. In general, the KC scheme in simulations \#1 and \#2 with $N_{\mathrm{IN}, 2}=1 \mathrm{~cm}^{-3}$ may underestimate the ice phase at warm temperatures and overestimate the ice phase at cold $T$. However, there is a clear qualitative agreement of the $\mathrm{KC}$ scheme in simulations \#1 and \#2 with the climatological data and parameterizations ECMWF and CAM3, although a further smoothing of the KC curve over the wider $T$-range is desirable, which is discussed below.

In contrast, the EDK09 simulations using the PDA08 parameterization, and simulations with the KC scheme in simulation \#3 with low concentrations $N_{\mathrm{IN}, 1}=N_{\mathrm{IN}, 2}=N_{\mathrm{IN}, 1}=$ $101^{-1}$ are in sharp conflict with climatology. EDK09 and $\mathrm{KC}$ simulation \#3 predict more than $95 \%$ liquid phase down to $-34.5^{\circ} \mathrm{C}$, where homogeneous nucleation begins to act in the drops with radii of $\sim 20 \mu \mathrm{m}$. With homogeneous nucleation, the PDA08 and KC run \#3 curves are very close and exhibit abrupt crystallization within a few tenths of a degree, and the curve $f_{1}(T)$ is actually vertical. The simulations in EDK09 show that the DW04 scheme produces ice crystals with concentrations similar to the $\mathrm{KC}$ scheme in simulations $\# 1$ and \#2, i.e., with the limits $3001^{-1}$ for dust and $10001^{-1}$ for soot, the corresponding limiting aerosol concentrations in the 2nd mode chosen in EDK09.

The low heterogeneous nucleation efficiency of the PDA08 scheme in ice production was somewhat masked in Fig. 2, where the characteristics of the liquid and ice phases were plotted separately, but it becomes clearer in Fig. 3, when considering the ratio of liquid to total water, $f_{1}(T)$. Figure 3 illustrates that the increase in LWC during the parcel ascent is so rapid that the small amount of ice nucleated with PDA08 scheme did not result in any noticeable crystal growth and liquid water depletion by the Bergeron-Findeisen mechanism. EDK09 argued that the KC and DW04 schemes produced crystal concentrations a few orders of magnitude greater and substantially overestimate ice production. However, Figs. 2 and 3 show that high crystal concentration is not a characteristic feature of the KC and DW04 schemes, it was a result of choosing a high value of input IN concentration $N_{\text {IN }} \sim 1 \mathrm{~cm}^{-3}$ for these schemes in EDK09.

Figure 3 shows that the KC scheme with higher values of $N_{\mathrm{IN}} \sim 1 \mathrm{~cm}^{-3}$ is much closer to reality in reproducing the cloud phase state (and the DW04 scheme also), while the PDA08 scheme and $\mathrm{KC}$ scheme with lower values of $N_{\text {IN }} \sim 0.01 \mathrm{~cm}^{-3}$ produces unrealistically high values of liquid water down to the threshold of homogeneous nucleation. It is not clear whether this is a consequence of the too low IN concentrations in PDA08 scheme and in KC simulation \#3, or a result of an unrealistic simulation with an isolated parcel model with high vertical velocities for a long time. This question can be answered by running Eulerian models with more realistic dynamic and physical framework with various ice schemes. The modifications of the DW04 immersion freezing scheme were applied by Lohmann and Diehl (2006) in the ECHAM4 general circulation model and by Zubler et al. (2011) in the nonhydrostatic weather prediction Consortium for Small-Scale Modeling (COSMO) model. In both works, ice nucleation was efficient well above $-35^{\circ} \mathrm{C}$ and DW04 scheme produced reasonable glaciation effects in good agreement with observations. To further address this question, the results of simulation of the observed in MPACE mixed cloud with a 1-D Eulerian model more realistic than a parcel model and KC scheme are described in Sect. 5.

\section{Assessment of parameterized ice particle concentrations}

Phillips et al. (2008) and EDK09 compared the PDA08 empirical parameterization of IN with that from KC theory and concluded that the $\mathrm{KC}$ approach produces $N_{\mathrm{c}}(T)$ curves with slopes $d N_{\mathrm{c}} / d T$ that are too steep and overestimate the crystal concentration $N_{\mathrm{c}}$. In this section, we show that PDA08 used an incorrect procedure of comparison, and not the $\mathrm{KC}$ data at all, and that a correct comparison shows good agreement of the KC scheme with observations.

Figure 4 shows the results of simulations of $N_{\mathrm{c}}$ with the parcel model described in $\mathrm{KC} 05$ and $\mathrm{KC}$ heterogeneous ice nucleation scheme. This figure includes simulations from KC05 based on several hundred runs of the parcel model, and results of several new runs are added along with our parameterization for $w=0.3$ to $50 \mathrm{~cm} \mathrm{~s}^{-1}$ and Cooper's (1986) parameterization. Each solid symbol in Fig. 4 corresponds to a final value of $N_{\mathrm{c}}$ after a single run of the parcel model with the KC scheme. This figure shows substantial variability of $N_{\mathrm{c}}$ that depends on the initial temperature $T$, vertical velocity $w$, contact parameter $m_{\mathrm{is}}$, and the area $\alpha$ of the active sites. The KC curves of $N_{\mathrm{c}}(T)$ have two distinct different slopes: a larger slope at $T<-18$ to $-20^{\circ} \mathrm{C}$ and a smaller slope for $T<-20^{\circ} \mathrm{C}$. The two different slopes are explained by the preferential ice nucleation with medium contact parameter $m_{\text {is }} \sim 0.5$ in mixed phase clouds at $T>-20^{\circ} \mathrm{C}$ (red symbols) and in ice clouds at colder temperatures (blue symbols). 


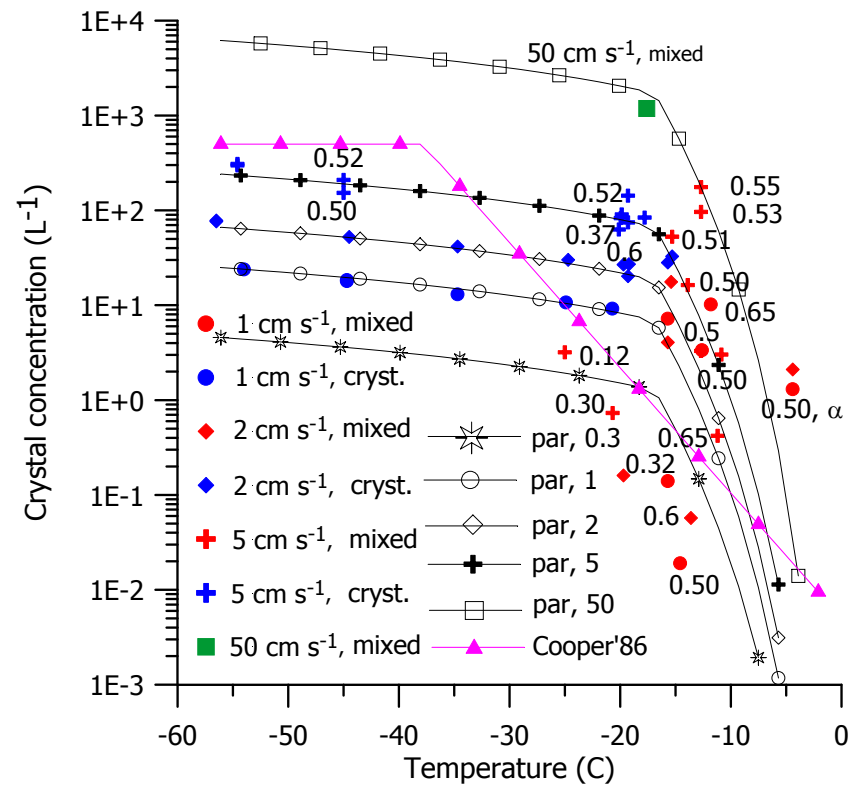

Fig. 4. Temperature dependence of the crystal concentrations $N_{\mathrm{c}}$ calculated with $w=1$ (solid circles), 2 (diamonds), and $5 \mathrm{~cm} \mathrm{~s}^{-1}$ (crosses), and $50 \mathrm{~cm} \mathrm{~s}^{-1}$ (green square). Each solid symbol corresponds to a final $N_{\mathrm{i}}$ after a single run of the parcel model with KC $(2000,2004,2005)$ heterogeneous DF ice nucleation scheme. The values of the contact parameter $m_{\text {is }}=0.52=$ const along the continuous lines, the other values of $m_{\mathrm{is}}$ are shown near the points that are outside the lines; the symbol " $\alpha$ " denotes the runs with $\alpha=2 \times 10^{-5}$. Red symbols denote $\mathrm{CCN}$ freezing at $\delta_{\mathrm{W}}>0$ in the presence of drops in a mixed cloud, mostly at $T_{\mathrm{c}}>-20^{\circ} \mathrm{C}$, although mixed phase can be below $-20^{\circ} \mathrm{C}$ and down to $-30^{\circ} \mathrm{C}$ with lower $m_{\text {is }}=0.12-0.30$. Blue symbols denote ice nucleation at $\delta_{\mathrm{W}}<0$ in a crystalline cloud. The solid lines with the open symbols plotted for $w=0.3,1,2,3,5$, and $50 \mathrm{~cm} \mathrm{~s}^{-1}$ are parameterizations from $\mathrm{KC05}$ of the simulation data as described in the text. These lines are compared with Cooper's (1986) parameterization (triangles). These fits might be used as a simple parameterization of the average data in Figure in cloud models and GCMs.

However, mixed-phase clouds may exist in these simulations down to $-30^{\circ} \mathrm{C}$ at lower values of $m_{\text {is }}$, which indicates that the $\mathrm{KC}$ scheme can be consistent with frequent observations of the mixed-phase Arctic clouds at low temperatures (Curry, 1986; Curry et al., 1990, 1993, 1996, 2000; Curry and Webster, 1999; Gultepe et al., 2000; Lawson et al., 2001; Intrieri et al., 2002; Korolev et al., 2003; Shupe et al., 2006; McFarquhar et al., 2007; Cotton and Anthes, 1989). A comparison with Cooper's (1986) parameterization limited at $N_{\mathrm{c}}=5001^{-1}$ shows that the slopes of the KC curves are greater at $T>-18^{\circ} \mathrm{C}$ and much smaller at colder $T$ in mostly crystalline clouds.

The solid lines with the open symbols in Fig. 4 represent a parameterization of the simulation data described in $\mathrm{KC} 05$ and modified here as a function of two variables, $T$ and $w$ :

$N_{\mathrm{c}}(T, w)=C_{\mathrm{g}}\left(T_{\mathrm{c} 0}-T_{\mathrm{c}}\right)^{C_{T}} w^{C_{\mathrm{w}}}$,

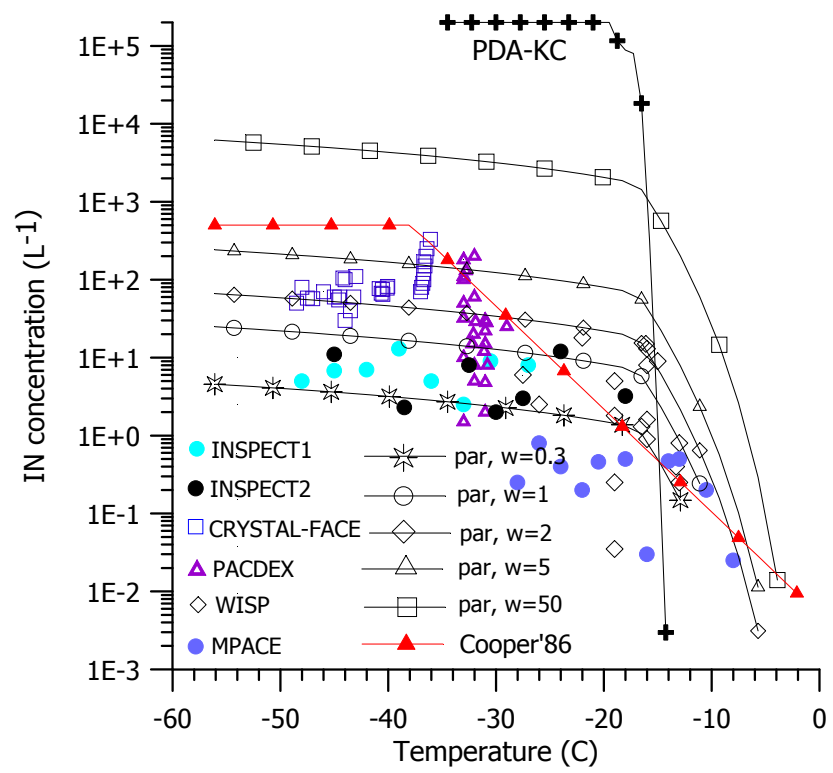

Fig. 5. Parameterized parcel model simulations from $\mathrm{KC}$ scheme with DF mode shown in Fig. 4 for the 5 values of $w=0.3,1,2$, 5 and $50 \mathrm{~cm} \mathrm{~s}^{-1}$ are compared to the experimental data from the 6 field campaigns described in Eidhammer et al. (2009) and indicated in the legend. The almost vertical curve labeled "PDA-KC" is from Philips et al. (2008). This curve, labeled "KC" in PDA08, was calculated from Eq. (7) for $N_{\mathrm{c}}$ here at $S_{\mathrm{W}}=1(\mathrm{RHW}=100 \%)$ for each $T$ separately, without any model simulations and was a wrong attempt to represent the $T$-dependence in $\mathrm{KC}$ theory with excluded $S_{\mathrm{W}}$-dependence and its negative feedback. As this figure illustrates, this curve is substantially different from the real $T$ dependences in $\mathrm{KC}$ scheme represented by the parameterized $\mathrm{KC}$ curves. This PDA-KC curve from PDA08 actually represents the old $T$-dependence from the classical theory based on the Thomson's (1888) equations for $r_{\mathrm{cr}}$ and $\Delta F_{\mathrm{cr}}$ with account for only $T$ dependence but without $S_{\mathrm{W}}$-dependence (see PK97, eq. 9-38).

where $T_{\mathrm{c}}$ is the temperature in Celsius, $T_{\mathrm{c} 0}=0{ }^{\circ} \mathrm{C}, N_{\mathrm{c}}$ is in $1^{-1}, C_{\mathrm{w}}=1.41$; and there are two sets of the other constants: $C_{\mathrm{g}}=0.4 \times 10^{-8}, C_{T}=8.0$, for $T_{\mathrm{c}}>-15^{\circ} \mathrm{C}$; and $C_{\mathrm{g}}=0.535, C_{\mathrm{T}}=1.05$ for $T_{\mathrm{c}}<-15^{\circ} \mathrm{C}$. The expression in Eq. (13) represents the average data in Fig. 4 and can be used as a simple parameterization in cloud models and GCMs. Zhang et al. (2011) successfully used this parameterization in the Weather Research and Forecast (WRF) model for simulations of dust effects on ice nucleation in the development of Hurricane Helene.

This parameterization (Eq. 13) is compared in Fig. 5 to the experimental data from the 6 field campaigns described in EDK09: INSPECT1, INSPECT2, CRYSTALFACE, PACDEX, WISP, and MPACE. Figure 5 shows that the span of the $\mathrm{KC}$ parameterization curves in the range $w=0.3-5 \mathrm{~cm} \mathrm{~s}^{-1}$ encloses the majority of the field data, i.e., this ice nucleation scheme is in general agreement with the field experiments. The tendency of $\mathrm{KC}$ curves is in 
qualitative agreement with Cooper's (1986) parameterization used in the Morrison microphysics scheme currently employed in the CAM3 GCM (Morrison and Gettelman, 2008; Gettelman et al., 2008) but allows a greater variability caused by the different cooling rates $(w)$. The almost vertical curve in Fig. 5, marked "PDA-KC", is from PDA08. This curve was labeled "KC" in PDA08 and was intended to represent the $T$-dependence in KC theory; however this curve was constructed in PDA08 for the first time without any parcel simulations and therefore is named here "PDA-KC". Figures 4 and 5 clearly illustrate that this "KC" curve in PDA08 does not correspond to the $\mathrm{KC}$ scheme and does not represent any real dependence of final $N_{\mathrm{c}}(T)$ from KC simulation data for various conditions. The "PDA-KC" curve differs from the KC simulations here in two aspects: (1) the slope of this curve is much steeper than that of the KC curves; (2) the maximum values of $N_{\mathrm{c}}\left(\sim 2 \times 10^{5} \mathrm{l}^{-1}\right)$ are $10^{3}-10^{5}$ times greater than on the $\mathrm{KC}$ curves. These differences are analyzed below.

The "PDA-KC" curve is almost vertical because ice nucleation in this case occurs in a very narrow $T$-range, in this case, $\sim-14$ to $-16^{\circ} \mathrm{C}$. This curve was plotted in PDA08 as a possible hypothetical temperature dependence of intermediate $N_{\mathrm{c}}(T)$, but it was calculated without any parcel model runs and with fixed $S_{\mathrm{w}}=1$ (or RHW $=100 \%$ ), that is, with excluded any supersaturation dependence. Phillips et al. (2008) in their "adiabatic" model considered ice crystal nucleation but neglected crystal growth and the BergeronFindeisen mechanism; therefore the liquid phase and mixed cloud with $S_{\mathrm{w}}=1$ exist in their model at all temperatures down to $-70^{\circ} \mathrm{C}$. This curve "PDA-KC" actually represents the old $T$-dependence based on the classical equations for $r_{\mathrm{cr}}(T)$ and $\Delta F_{\mathrm{cr}}(T)$ by Thomson (1888) with account for only the $T$-dependence and without any $S_{\mathrm{w}}$-dependence (see eq. 9-38 in PK97 or Eq. (4a) here with $S_{\mathrm{w}}=1, H_{\mathrm{v}, \mathrm{fr}}=0$ ). It has long been known that early formulations of the classical nucleation theory produce unrealistic values of $N_{\mathrm{c}}$. PDA08 characterized this curve as a $T$-dependence in the $\mathrm{KC}$ scheme, but it is an incorrect characterization because the $T$-dependence in the KC parcel model simulations shown in Figs. 4,5 was calculated with account for the $S_{\mathrm{w}}$-dependence and its negative feedback that reduces $N_{\mathrm{c}}$ by several orders of magnitude. The KC curves correspond to many nucleation events that begin at different initial conditions $\left(T, S_{\mathrm{w}}\right)$ and pass different trajectories on the $S_{\mathrm{w}}-T$ phase plane, and the temperature in $\mathrm{KC}$ data is the final temperature when nucleation has ceased.

The very large values of $N_{\mathrm{c}}$ that are 3-5 orders of magnitude higher than typical $N_{\mathrm{c}}$ were produced by PDA08 due to two reasons. (1) PDA08 used only Eq. (8a) for $N_{\mathrm{c}}$ with very high IN concentration $N_{\mathrm{ai}}=200 \mathrm{~cm}^{-3}=2 \times 10^{5} 1^{-1}$, which resulted in this high $N_{\mathrm{c}}$ on PDA-KC curve. If $N_{\text {ai }}$ was chosen comparable to typical CFDC data of $1-201^{-1}$, then $N_{\mathrm{c}}$ would be several orders of magnitude smaller. (2) Further, PDA08 fixed $S_{\mathrm{w}}=1$ and therefore neglected very strong negative su- persaturation feedback in the $\mathrm{KC}$ scheme (see KC05). If the correct $S_{\mathrm{w}}$-dependence is included as in the KC scheme, then $S_{\mathrm{w}}$ can be equal to 1 for some time, but eventually becomes negative at some $N_{\mathrm{c}}$ due to the supersaturation absorption by the drops (if any) and crystals, this creates a very strong exponential negative feedback and nucleation ceases at values of $N_{\mathrm{c}}$ represented by KC points in Fig. 4 and curves in Fig. 5 that are 3-5 orders of magnitude smaller than those on the "PDA-KC" curve. Therefore the PDA08 interpretation of the KC theory with very high $N_{\mathrm{ai}}$ and excluded $S_{\mathrm{w}^{-}}$ dependence is an incorrect and misleading representation of the KC parameterization. The strong negative feedback due to $S_{\mathrm{w}}$-dependence found and analyzed in KC05 bounds $N_{\mathrm{c}}$ and produces much smoother $N_{\mathrm{c}}(T)$ and parameterization that are in a good general agreement with the data from 6 field campaigns as shown in Fig. 5.

Figure 6 shows $N_{\mathrm{c}}\left(s_{\mathrm{i}}\right)$ calculated with KC scheme and another comparison with experimental data by Rogers (1982, 1988) and Al-Naimi and Saunders (1985), now as a function of ice supersaturation. Plotted here are also two previous empirical parameterizations, MDC92 (green) and Huffman's (1973) power law $N_{\mathrm{c}}\left(s_{\mathrm{i}}\right)=C_{\mathrm{iH}} s_{\mathrm{i}}^{b_{\mathrm{H}}}$ (magenta). Huffman found $3<b_{\mathrm{H}}<8$, and $C_{\mathrm{iH}}$ was more uncertain. We have chosen here the values $C_{\mathrm{iH}}=10^{-5} 1^{-1}$ and $b_{\mathrm{H}}=4.9$ to match the lab data. Each solid symbol on the theoretical curves or nearby (red, blue and brown) corresponds to a final $N_{\mathrm{c}}$ (after nucleation ceases) in a single run of the parcel model plotted against the maximum value of $s_{\mathrm{i}}$ during the run (reached usually near maximum $N_{\mathrm{c}}$ ). The points from parcel simulations with KC scheme are here the same as in Fig. 4 for $N_{\mathrm{c}}(T)$ but plotted now versus $s_{\mathrm{i}}$.

Figure 6 shows that $\mathrm{KC}$ values of $N_{\mathrm{c}}$ are in reasonable qualitative and quantitative agreement with the experimental points and both previous parameterizations, showing an increase of $N_{\mathrm{c}}\left(s_{\mathrm{i}}\right)$ with increasing $s_{\mathrm{i}}$. However, the simulated increase is different for both small and large values of $s_{\mathrm{i}}$ : there is a distinct decrease of the slopes $d N_{\mathrm{c}}\left(s_{\mathrm{i}}\right) / d s_{\mathrm{i}}$ at $s_{\mathrm{i}}>15-20 \%$, i.e., some sort of "saturation" at higher $s_{\mathrm{i}}$. This feature, convex dependence $N_{\mathrm{c}}\left(s_{\mathrm{i}}\right)$ with decreasing slopes, is similar to Huffman's parameterization and to the water supersaturation dependence in the drop nucleation power law (e.g., Yum and Hudson, 2001; Khvorostyanov and Curry, 2006, 2007).

\section{Simulations of Mixed-Phase Arctic Cloud Experiment (MPACE)}

It was mentioned in Sect. 3 that parcel models alone are insufficient tools for testing various ice parameterizations, and Eulerian models are needed. An Eulerian single-column model with KC scheme is used in this section for simulation of the long-lived mixed-phase clouds that occur in the Arctic. Simulation of Arctic mixed-phase clouds is one of 


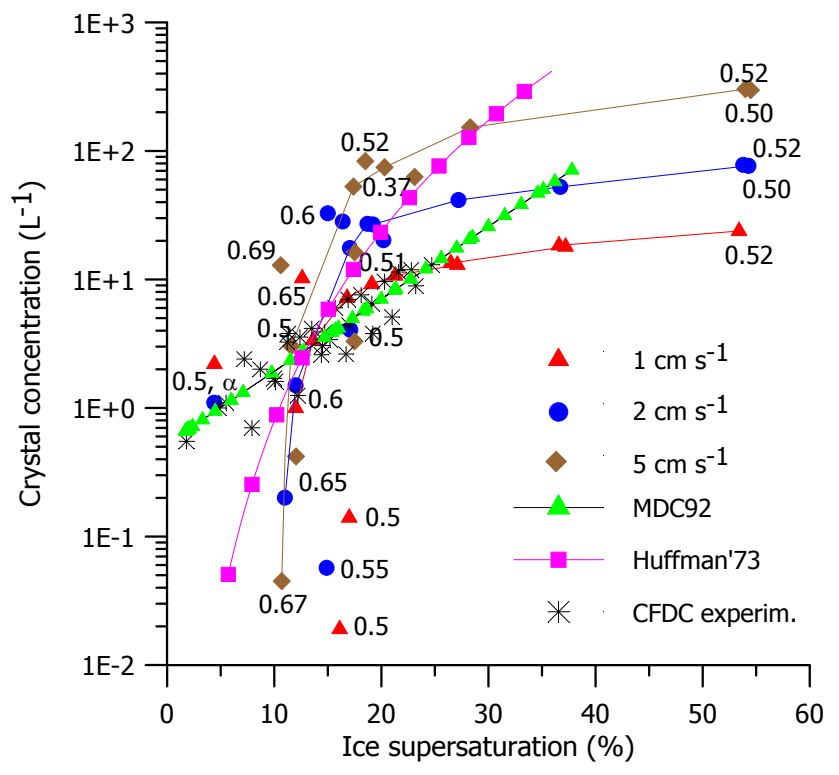

Fig. 6. The ice supersaturation dependence of the crystal concentration $N_{\mathrm{c}}\left(s_{\mathrm{i}}\right)$ calculated with $\mathrm{KC} 04-\mathrm{KC} 05$ scheme. Each solid circle on the curves corresponds to a final $N_{\mathrm{c}}$ after a single run of the parcel model with $\alpha=0$. The data are mostly the same as in Fig. 4 but plotted here as a function of ice supersaturation. The red, blue and brown symbols and lines denote simulations with vertical velocity $w=1,2$ and $5 \mathrm{~cm} \mathrm{~s}^{-1}$. The contact parameter $m_{\text {is }}=0.52$ along the lines (as shown at the right ends) and is indicated near the points where it is different from 0.52 ; the symbol " $\alpha$ " denotes the runs with active site parameter $\alpha=2 \times 10^{-5}$, which yields $N_{\mathrm{c}}=1-31^{-1}$ at $s_{\mathrm{i}} \approx 5 \%$. With this or similar value $\alpha$, all points would be shifted to lower supersaturations by $\sim 5-7 \%$ and would be closer to MDC92 curve and experimental points at lower ice supersaturations. The parameterization curve from Meyers et al. (MDC92, extended to $s_{\mathrm{i}}=38 \%$ ) is denoted with green color and triangles. Huffman's (1973) parameterization $N_{\mathrm{c}}\left(s_{\mathrm{i}}\right)=C_{\mathrm{iH}} s_{\mathrm{i}}^{\mathrm{b}}$ with $C_{\mathrm{iH}}=10^{-5} 1^{-1}$ (chosen here to match the lab data) and $b=4.9$ is shown in magenta. Black crosses denote experimental points from CFD chamber by Rogers $(1982,1988)$ and Al-Naimi and Saunders (1985) (courtesy by Paul DeMott).

the greatest challenges for a heterogeneous ice nucleation parameterization.

The Mixed-Phase Arctic Cloud Experiment (MPACE) was conducted during September-October 2004 at the North Slope of Alaska site in the vicinity of the ARM Climate Research Facility (Verlinde et al., 2007). A single-layer mixedphase stratocumulus cloud deck with boundaries from 0.40.5 to $1.3-1.6 \mathrm{~km}$ was observed on 9-11 October, when the air mass was advected from the pack ice to the open ocean and further inland (Klein et al., 2006; Verlinde et al., 2007). The temperature varied from approximately around $-8^{\circ} \mathrm{C}$ at cloud base to -15 to $-17^{\circ} \mathrm{C}$ at cloud top (McFarquhar et al., 2007). Data on condensation nuclei were absent due to instrument malfunction onboard of Citation aircraft. The dry aerosol size distributions were obtained with Hand-Held Par- ticle Counter (HHPC) on the Aerosonde unmanned aircraft, but aerosol composition was unknown, and some condensation nuclei data were collected by the counter operated in Barrow.

The average aerosol measurements on 10 October were approximated by a bimodal aerosol size spectrum that was recommended for use in numerical models (Klein et al., 2006). The parameters for the fine mode were: concentration $N_{\mathrm{a} 1}=72.2 \mathrm{~cm}^{-3}$, mean geometric radius $r_{\mathrm{g} 1}=0.052 \mu \mathrm{m}$, and dispersion $\sigma_{\mathrm{d} 1}=2.04$; the corresponding parameters for the coarse mode were $N_{\mathrm{a} 2}=1.8 \mathrm{~cm}^{-3}$, mean geometric radius $r_{\mathrm{g} 2}=1.3 \mu \mathrm{m}$, and dispersion $\sigma_{\mathrm{d} 1}=2.5$. The aerosol data were collected in the subcloud layer but should be representative of the entire atmospheric boundary layer (ABL) including the cloud because it was well mixed (Verlinde et al., 2007).

The data on IN were sampled onboard the Citation with a CFDC having an upper radius limit of $0.75 \mu \mathrm{m}$. $96 \%$ of the data remained below the CFDC detection limit of about $0.11^{-1}$, although measured crystal concentrations varied in the range $1-301^{-1}$ (Fridlind et al., 2007). We can hypothesize two possible reasons for this. One reason could be that the CFDC radius limit, $0.75 \mu \mathrm{m}$, was substantially lower than the mean radius of the second aerosol mode, $1.3 \mu \mathrm{m}$. Thus, the IN particles in the tail of the 2 nd aerosol mode with maximum surface area and potentially highest ice nucleability were excluded from CFDC measurements, while the concentration of large particles only $0.01 \mathrm{~cm}^{-3}=101^{-1}$ would produce a significant effect. An additional explanation could be that the time of IN processing in the CFD chamber, 7$15 \mathrm{~s}$ (Rogers, 1982, 1988; PDA08), is much smaller than the timescale of heterogeneous ice nucleation of 15-240 min determined from models (e.g., Lin et al., 2002; KC05; EDK09). So, the IN concentrations above detection limit were measured only during $4 \%$ of the in flight measurement time, when IN concentration reached $1-201^{-1}$. Published simulations of this case used the average value of $0.16-0.21^{-1}$, which was determined as the average of 0 (below the detection limit) and the highest values of IN (Prenni et al., 2007; Fridlind et al., 2007; Morrison et al., 2008).

Several simulations of MPACE clouds have been performed with various models and ice nucleation parameterizations. Prenni et al. (2007; hereafter P07) used the Regional Atmospheric Modeling System (RAMS, Cotton et al., 2003) with heterogeneous ice nucleation parameterized using MDC92 and its modification with the same the functional form as Eq. (1) but with different coefficients $a_{\mathrm{M}}=-1.488$, $b_{\mathrm{M}}=0.0187$. $\mathrm{P} 07$ found that simulations with MDC92 led to rapid cloud glaciation even with depletion of IN, lack of liquid water and small optical thickness. Simulations with the modified MDC92 scheme (P07 ice scheme) and depletion of IN produced a mixed-phase cloud deck with sufficient liquid phase similar to observations. Simulations with the P07 scheme and IN increased by a factor of 2 and 10 (to $\sim 0.4-21^{-1}$ ) still yielded a mixed cloud and liquid phase was 
maintained for $24-48 \mathrm{~h}$. However, simulations using the P07 scheme without IN depletion led again to rapid glaciation.

Fridlind et al. (2007) simulated the MPACE cloud using a 3-D LES model with size-resolved bin microphysics. Several pathways of ice nucleation were parameterized in the model including the four standard modes of pristine ice nucleation, various modes of ice multiplication, and a few additional mechanisms. These mechanisms included: increase of IN aloft by 3 orders of magnitude from 0.2 to $2001^{-1}$, surface source of IN, prescription of some arbitrary rates of volume and surface freezing, slower sedimentation plus fragmentation, ice nuclei formation from drop evaporation residues, and drop freezing during evaporation. Fridlind et al. (2007) found that the ambient IN as measured by CFDC appeared insufficient by several orders of magnitude to explain the observed cloud phase state, particularly crystal concentrations and IWC. Sensitivity tests showed that neither standard 4 heterogeneous ice nucleation modes, nor 2 common ice multiplication mechanisms (drop shattering and crystal fragmentation due to ice-ice collisions) could explain the observed cloud microstructure and phase state. The standard nucleation modes and even an increase of IN by 3 orders aloft (run $2001^{-1}$ ) could produce only $N_{\mathrm{c}}$ generally smaller than $1-$ $21^{-1}$. The runs with either evaporation freezing or with evaporation IN produced total crystal concentrations of $101^{-1}$ and greater. This however did not cause full cloud glaciation and vertical profiles of LWC were similar to observed values with maxima about $0.5 \mathrm{~g} \mathrm{~m}^{-3}$ at a height $1200 \mathrm{~m}$. Both LWP and IWP were also similar to observed values in these runs.

Morrison et al. (2008) simulated MPACE clouds using the polar version of mesoscale MM5 model with two-moment microphysics scheme (Morrison et al., 2005; Morrison and Pinto, 2005). Two different modes of ice nucleation were included: deposition, condensation-freezing and immersionfreezing were considered as a single mode with a specified value of IN concentration of $0.161^{-1}$; and contact nucleation was parameterized with the temperature dependence following MDC92. The model was able to reproduce the LWC and drop concentrations in reasonable agreement with observations but could not capture ice phase properties as well. The modeled crystal concentration was smaller than observed by about an order of magnitude, which was a consequence of the large discrepancy between the measured IN and ice crystal concentrations. The sensitivity to ice nuclei concentration was tested by increasing IN by 10 and 100 times in the runs IN $\cdot 10$ (to $1.61^{-1}$ ) and IN $\cdot 100$ (to $161^{-1}$ ). The simulation IN $\cdot 10$ produced crystal concentrations much closer to observations while was still able to reproduce reasonably the liquid phase properties although $\mathrm{LWP}=158 \mathrm{~g} \mathrm{~m}^{-2}$ was somewhat smaller than observed. The simulation IN $\cdot 100$ (with IN comparable with the highest values in Fridlind et al., 2007) produced IWP of $30 \mathrm{~g} \mathrm{~m}^{-2}$, about 5-7 times smaller than observed.

The Prenni et al. (2007), Fridlind et al. (2007), and Morrison et al. (2008) simulations can be ranked according to sen- sitivity to presence of ice. The RAMS bulk model (Prenni et al., 2007) is most sensitive, full glaciation occurs at $N_{\mathrm{c}}$ $\sim 0.21^{-1}$ without depletion; the MM5 model with Morrison's microphysics is intermediate, mixed-phase can exist at $N_{\mathrm{c}} \sim 1.61^{-1}$; and the spectral bin model (Fridlind et al., 2007) allows existence of quasi-stationary mixed-phase cloud with the highest $N_{\mathrm{c}} \sim 5-101^{-1}$. A detailed comparison of 17 single column models (SCM) and 9 cloud resolving models (CRM) performed in Klein et al. (2009) and Morrison et al. (2009) showed a great diversity of simulated crystal concentrations (about five orders of magnitude).

Fan et al. (2009, hereafter F09) simulated this singlelayer mixed-phase cloud observed from MPACE using a 3-D model with spectral bin microphysics. The heterogeneous ice nucleation scheme chosen by F09 was more detailed than in most of the previous models: the KC scheme with simultaneous account for the temperature and supersaturation dependencies but with very low input IN concentration of $0.21^{-1}$, an artificial time average of the measured IN, and lower than the measured crystal concentrations $N_{\mathrm{c}}$ cited above. This was referred to as HIN_KC in F09, and this was an incorrect use of the $\mathrm{KC}$ scheme, because the output data (IN concentrations smaller than $N_{\mathrm{c}}$ ) were used instead of the required input IN data. Therefore, as noted in F09, the HIN_KC scheme in F09 could produce a maximum of only $0.21^{-1}$ even when all IN are activated. Thus, this HIN_KC scheme failed to reproduce the observed ice crystal concentration and F09 introduced two additional hypothetical mechanisms of ice nucleation enhancement considered in Fridlind et al. (2007): (a) activation of droplet evaporation residues by condensation followed by freezing, and (b) droplet evaporation freezing by contact freezing inside out.

Examination of F09 indicates that failure to reproduce the observed cloud with the KC scheme was caused by incorrect choice by F09 of the concentration of the initial freezing aerosol particles in $\mathrm{KC}$ scheme. Here we test the $\mathrm{KC}$ scheme with an Eulerian model, showing that correct use of the $\mathrm{KC}$ ice scheme with the DHetF nucleation mode and more correctly chosen input concentration $N_{\mathrm{ai}}$ may produce reasonable crystal concentrations in quite good agreement with the MPACE observations. The MPACE cloud is simulated using a 1-D single-column type model with spectral bin microphysics and supersaturation equation similar to described in Khvorostyanov et al. (2001, 2003, 2006). This spectral Eulerian model was under development for almost $40 \mathrm{yr}$, was used previously for simulations of the natural formation and artificial seeding of all the major cloud types (a review is in Khvorostyanov, 1995), in particular, for the mixedphase clouds observed during the SHEBA-FIRE experiment in 1998 (Curry et al., 2000): in a 1-D version for simulation of a deep frontal mixed-phase cloud of St-As-cirrus, and in a 3-D version for a boundary layer cloud formed over the Beaufort Sea polynya (Khvorostyanov et al., 2001, 2003), in a 2-D version for simulation of the moderately cold cirrus (Sassen et al., 2002) and in a 1-D version for simulation with 
KC DHetF ice scheme of a very cold cirrus observed during the CRYSTAL-FACE campaign in 2002 (Khvorostyanov et al., 2006). The version of the model used for the MPACE simulations was modified to include a revised droplet nucleation scheme following a generalized power law derived in $\mathrm{KC} 06, \mathrm{KC} 07$ as described in Sect. 3.

The aerosol measured in MPACE was approximated by the two lognormal modes, fine and coarse, as described above based on Klein et al. (2006, 2009), Morrison et al. (2008). The KC scheme was tested in 2 simulations: (a) both fine mode with $r_{\mathrm{g} 1}=0.052 \mu \mathrm{m}$ and coarse mode with $r_{\mathrm{g} 2}=$ $1.3 \mu \mathrm{m}$ were allowed to serve as $\mathrm{CCN}$ and IN; (b) only coarse mode with $r_{\mathrm{g} 2}=1.3 \mu \mathrm{m}$ was allowed to serve as IN, similar to the parcel simulations in EDK09 and ours in Sect. 3. We first describe in detail results in the simulation (b) and then compare with simulation (a).

The model was initialized using the initial and boundary conditions provided by Klein et al. (2006), Xie et al. (2006a, b). The cloud was initially pure liquid and the drop spectra were initialized as a 3-parameter gamma distribution with a power index of 6 using observed profiles of LWC and $N_{\mathrm{d}}$ (Klein et al., 2006; see Figs. 1 and 2). Subsequently, the two kinetic equations for the droplet and crystal size distribution functions were solved at each time step $\Delta t=0.5 \mathrm{~s}$ along with the supersaturation equation to calculate the evolution of the liquid and ice size spectra, each including 30 gridpoints by radius. The model has 61 vertical levels with $\Delta z=25 \mathrm{~m}$, corresponding to a vertical domain of $1.5 \mathrm{~km}$. The algorithms of solution were described in detail in Khvorostyanov et al. (1995, 2001, 2003, 2006).

The baseline simulated height-time display for the MPACE cloud is shown in Fig. 7. Initially, there is a rather thick liquid layer with slightly positive water supersaturation, and ice supersaturation reaches 15-18\% (Figs. 7a, b). Maximum droplet concentration and liquid water content (LWC) are $90 \mathrm{~cm}^{-3}$ and $0.4 \mathrm{~g} \mathrm{~m}^{-3}$ (Fig. $7 \mathrm{c}$, e) in the upper cloud layer above $1 \mathrm{~km}$. Crystals appear after $30 \mathrm{~min}$ of simulation, in a narrow layer near the temperature minimum $\left(\sim-15^{\circ} \mathrm{C}\right)$ at $z=1.3 \mathrm{~km}$ with RHW $\sim 100 \%$ (Fig. $7 \mathrm{~d}, \mathrm{f}$ ). Maximum crystal concentrations $N_{\mathrm{c}}$ are $20-301^{-1}$ in the generating layer, ice virga fall out from it, and $N_{\mathrm{c}} \sim 5-101^{-1}$ in the lower layers, generating precipitation that reaches the surface.

The simulated ice nucleation has an oscillatory character (clearly seen in Fig. 7f) that results from competition between supersaturation production by dynamical and radiative forcings and supersaturation depletion due to vapor deposition to the drops and crystals. These oscillations resemble those in the evolution of the cirrus clouds with homogeneous ice nucleation (Sassen and Dodd, 1989; Khvorostyanov et al., 2001; Sassen et al., 2002). Complete glaciation of the simulated cloud does not occur, since the crystal concentrations are too low and their supersaturation relaxation times are $1-1.5 \mathrm{~h}$ (Fig. 1j), the rate of vapor deposition is low, and the Bergeron-Findeisen mechanism acts slowly. Supersaturation over water is close to zero in most of the cloud layer even in the presence of the crystals with these concentrations of $10-301^{-1}$, and a rather large ice supersaturation of $\sim 10$ $20 \%$ exists in the cloud layer. It is not rapidly converted into IWC in contrast to many bulk models with zero ice supersaturation. This feature is described by the supersaturation equation in this model, and allows to cloud to exist in the mixed-phase state for a long time and to reach a quasi-steady state with very slow gradual accumulation of ice content. The crystal concentrations of $5-15 \mathrm{l}^{-1}$ do not cause full glaciation due to the large crystal relaxation time and high residual quasi-steady ice supersaturation. This result is in a good agreement with the more detailed simulations performed earlier with the 2-D version of this model by M. Khairoutdinov and M. Ovtchinnikov with wide variations of the crystal concentrations (e.g., Khairoutdinov and Khvorostyanov, 1989; Kondratyev et al., 1990a, b, c), which showed that even higher crystal concentrations may not cause full cloud glaciation due to maintenance of the residual ice supersaturation instead of its fast transformation into bulk ice, and allowed to find the criteria for full glaciation.

Figure 8 compares the simulated vertical profiles of $N_{\mathrm{d}}$, $N_{\mathrm{c}}$, LWC, and IWC for the MPACE case on 10 October 2006 with the observational data. It is noted here that the largescale flow pattern and cloud field varied little during 9-10 October (Verlinde et al., 2007; Morrison et al., 2008). The simulated droplet concentration is close to the initial profile, and maximum LWC decreased to $0.3 \mathrm{~g} \mathrm{~m}^{-3}$. Simulated crystal concentration in the upper layer $0.75-1.5 \mathrm{~km}$ closely resembles the measured $N_{\mathrm{c}}$ : there is a pronounced maximum in $N_{\mathrm{c}} \sim 301^{-1}$ at $\sim 1.25 \mathrm{~km}$, both in simulations and observations, that coincides with the temperature minimum -15 to $-16.5^{\circ} \mathrm{C}$, where a substantial increase in ice nucleation rate via the DHetF mode is predicted the by $\mathrm{KC}$ theory ( $\mathrm{KCO}$, KC04b, KC05).

Thus, this simulation shows that the KC scheme in DHetF mode is capable of explaining many features of the crystal concentrations observed during MPACE and coexistence of the liquid and ice phases. The lower maximum near $0.5 \mathrm{~km}$ in measured $N_{\mathrm{c}}$ is not reproduced by the model. The origin of this maximum could be a result of the nucleation due to evaporated droplet residues or droplet freezing near the lower cloud boundary as suggested in Fridlind et al. (2007), this mechanism was not accounted for in our simulations.

The simulation (a) with both fine and coarse modes allowed for ice nucleation showed very little difference with simulation (b). Thus, it appears that the $\mathrm{CCN}$ fraction plays minor role in ice nucleation compared to the coarse mode. The reason for this is that, as follows from Eq. (7), the nucleation rate for an individual aerosol particle is proportional approximately to the square of particle radius, i.e., to its surface area. For a population of particles, it was shown in KC05 that Eqs. (7) for $J_{\text {het }}$ and (9) for $R_{\mathrm{fr}}$ can be simplified in such a way that the integrals for the crystal concentration and nucleation rate contain explicitly the surface area of aerosol population. The ratio of surface areas of the 

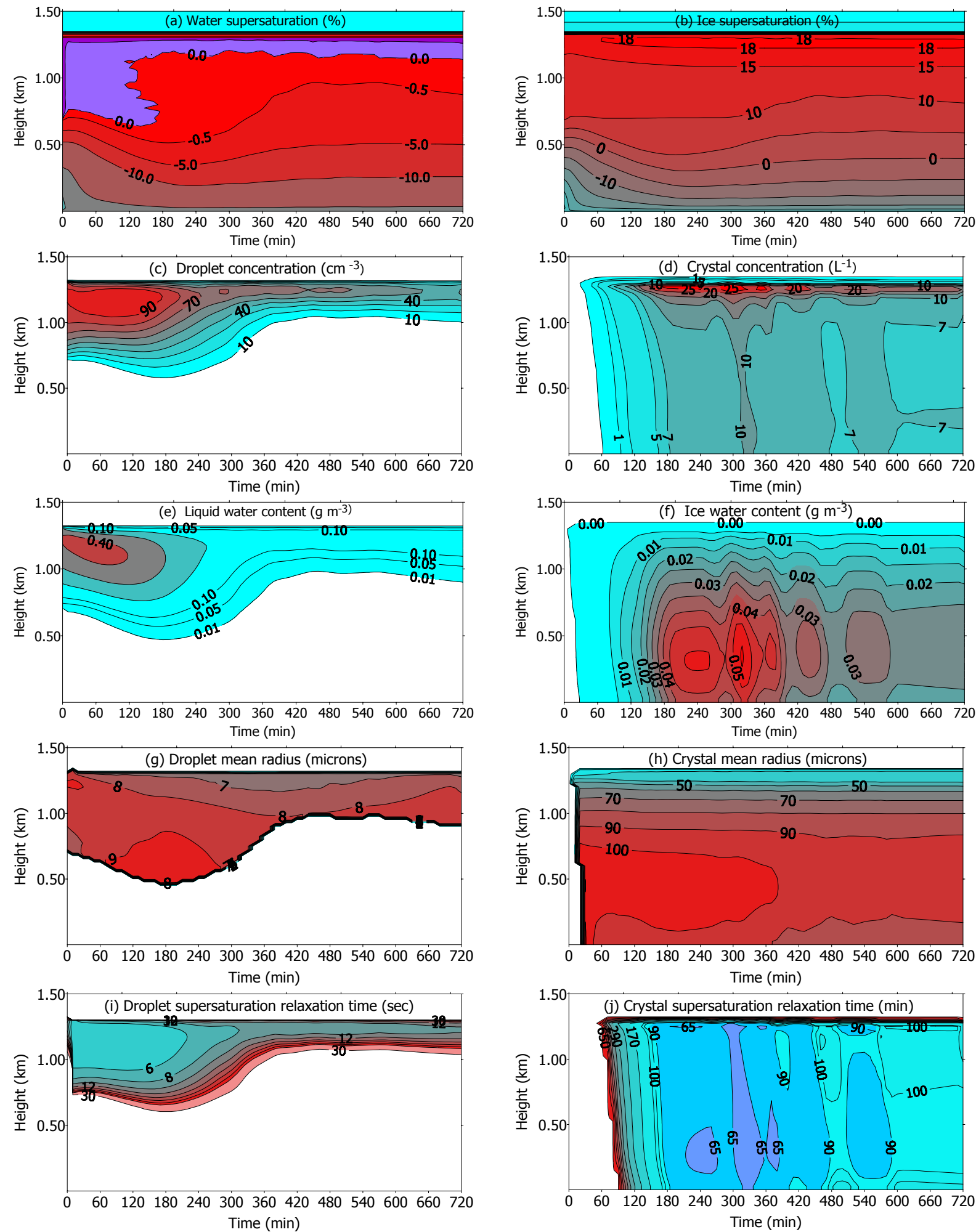

Fig. 7. Evolution of the Arctic mixed-cloud microphysical properties over $12 \mathrm{~h}$ with initial M-PACE data on 10 October 2004 , KC ice scheme with deliquescence-heterogeneous-freezing (DHetF) mode only and KC06-07 drop activation scheme. In this simulation, the aerosol of the fine observed lognormal mode $\left(N_{\mathrm{a} 1}=72.2 \mathrm{~cm}^{-3}, r_{\mathrm{m}}=0.052 \mu \mathrm{m}, \sigma_{1}=2.04\right)$ was allowed to serve as CCN; the aerosol of the coarse observed lognormal mode $\left(N_{\mathrm{a} 2}=1.8 \mathrm{~cm}^{-3}, r_{\mathrm{m}}=1.3 \mu \mathrm{m}, \sigma_{2}=2.5\right)$ was allowed to serve as ice nuclei and participate in nucleation processes. 

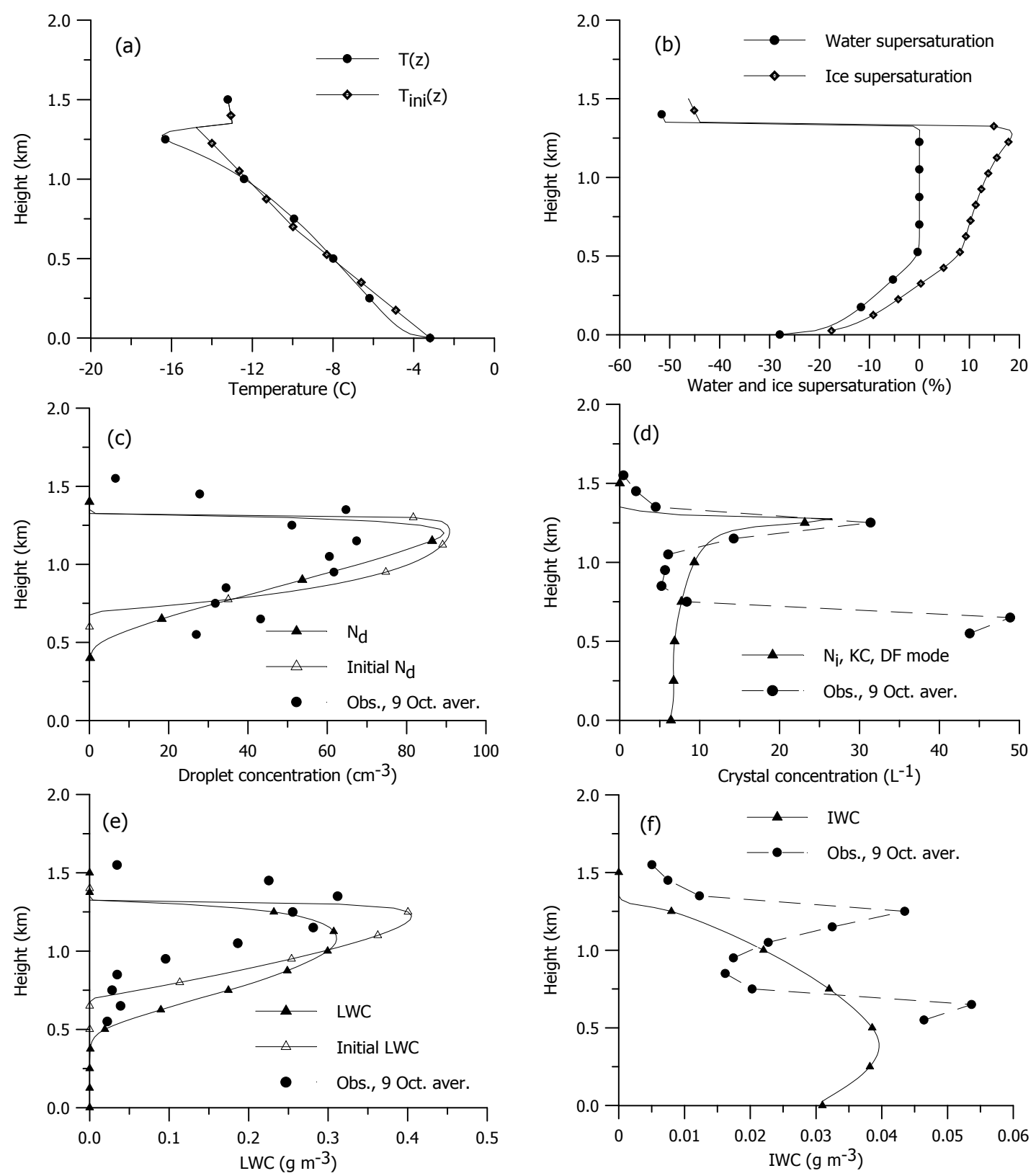

Fig. 8. Vertical profiles of $N_{\mathrm{d}}, N_{\mathrm{i}}$, LWC, and IWC for simulations of MPACE on 10 October 2006, corresponding to the time $t=3 \mathrm{~h}$ in cross-sections in Fig. 7, compared to the observational data for 9 October. KC ice nucleation scheme was used with account for DHetF mode, and KC06-07 CCN activation scheme was used for drop nucleation. In this simulation, the aerosol of the fine observed lognormal mode $\left(N_{\mathrm{a} 1}=72.2 \mathrm{~cm}^{-3}, r_{\mathrm{m}}=0.052 \mu \mathrm{m}, \sigma_{1}=2.04\right)$ was allowed to serve as $\mathrm{CCN}$; the aerosol of the coarse observed lognormal mode $\left(N_{\mathrm{a} 2}=1.8 \mathrm{~cm}^{-3}, r_{\mathrm{m}}=1.3 \mu \mathrm{m}, \sigma_{2}=2.5\right)$ was allowed to serve as ice nuclei. Note a pronounced maximum in $N_{\mathrm{i}}$ at $\sim 1.25 \mathrm{~km}$, both in simulations and observations, that coincides with the temperature minimum -16 to $-16.5^{\circ} \mathrm{C}$, where a substantial increase in ice nucleation rate is predicted by $\mathrm{KC}$ theory $(\mathrm{KC} 04, \mathrm{KC} 05)$.

coarse and fine fractions in MPACE can be roughly estimated as $r_{\mathrm{g} 2}^{2} / r_{\mathrm{g} 1}^{2} \sim(1.3 / 0.05)^{2}=(26)^{2}=676$. The ratio of the concentrations is $N_{2} / N_{1}=1.8 / 72=0.025$. Thus, the ratio of ice nucleation abilities of these modes is $\sim N_{2} r_{\mathrm{g} 2}^{2} / N_{1} r_{\mathrm{g} 1}^{2}$ $\sim 676 \times 0.025=17$, i.e., the ice nucleating ability of the coarse fraction is about 17 times greater than that of the fine fraction (and unfortunately, this coarse mode could not be captured by the CFDC). This is a crude estimate but it illustrates the major role of the coarse fraction and the small difference between the two simulations. Note that in this explanation, the ratio of concentrations of IN to $\mathrm{CCN}$ is small, $N_{2} / N_{1}=0.025$, in agreement with experimental results (e.g., PK97, DeMott et al., 1998). 
As Figs. 7 and 8 illustrate, correct application of the KC scheme produces quite reasonable values and profiles of $N_{\mathrm{i}}$ close to observed, and shows that F09's conclusion that “... HIN_KC... cannot produce the observed ice crystal concentrations without ice enhancement mechanisms" was based on an incorrect application of the $\mathrm{KC}$ scheme. If input IN concentration was chosen in F09 comparable to the coarse fraction, $\sim 1-2 \mathrm{~cm}^{-3}$ (as EDK09 used KC scheme) or perhaps even smaller but comparable, this would yield correct crystal concentrations using the $\mathrm{KC}$ scheme.

Other examples of successful applications of KC DhetF scheme in Eulerian models that also yielded reasonable $N_{\mathrm{c}}$ and cloud phase state close to observations include: a mixed Sc cloud over a polar polynya (Khvorostyanov et al., 2003), a cirrus cloud observed in CRYSTAL-FACE (Khvorostyanov et al., 2006), observed with lidar gradual glaciation of mixed Ac around $-15^{\circ} \mathrm{C}$ (Sassen and Khvorostyanov, 2007), and effects of forest fire smoke on the "reverse" formation of mixed Ac clouds when crystals formed first via haze freezing and cloud drops formed $10-15$ min later (Sassen and Khvorostyanov, 2008), dust effects on extended cloud system of the Hurricane Helene (Zhang et al., 2011).

\section{Conclusions}

Some empirical parameterizations of heterogeneous ice nucleation for cloud and climate models were analyzed and compared with the theoretical scheme developed by the authors (KC scheme) and based on a modification of the classical nucleation theory for freezing. The results can be briefly summarized as follows.

Analysis of several frequently used empirical parameterizations of heterogeneous ice nucleation in the context of extended classical nucleation theory based on the entropy equation indicates that most empirical parameterizations can produce reasonable crystal concentrations but are prohibited in some ranges of their variables (temperature and supersaturation) from the thermodynamic point of view since they correspond to negative critical ice germs radii or to humidities below the critical threshold. This indicates that the existing empirical parameterizations should be corrected, applied in the regions of their validity and those developed in the future should be constructed with account for the thermodynamic constraints. These thermodynamic limitations also should be accounted when evaluating various parameterizations in cloud models.

A detailed comparison of the empirical parameterization by Phillips et al. (2008) with the theoretical approach by Khvorostyanov and Curry (2000-2009) is performed using parcel model simulations similar to those in Eidhammer et al. (2009). Both schemes are compared with climatological data on cloud phase and with its parameterization in several GCMs. This comparison demonstrated that the PDA08 scheme as applied in EDK09 in the wide temperature range has a low nucleating efficiency, and may substantially underestimate crystal concentrations. In the EDK09 simulations, PDA08 scheme predicts almost entirely liquid cloud down to $-35^{\circ} \mathrm{C}$, the threshold of homogeneous nucleation. The KC scheme is sufficiently flexible and its performance depends on the choice of the input parameters. The KC scheme with IN concentration of $1 \mathrm{~cm}^{-3}$ as chosen in EDK09 and here yields the temperature dependence of the cloud phase much closer to climatology. A simulation using the $\mathrm{KC}$ scheme and 3 fractions of IN with much smaller concentrations of $0.01 \mathrm{~cm}^{-3}\left(101^{-1}\right)$, comparable to measured in CFDC, produced crystal concentrations comparable to those in PDA08 and EDK09, and the cloud phase state similar to EDK09, almost liquid down the threshold of drop homogeneous freezing. It is not clear whether this liquid phase is a consequence of too low IN concentrations, or a result of an unrealistic simulation with an isolated parcel model with high vertical velocities for a long time causing "superproduction" of liquid.

The conclusion drawn in EDK09 that the KC scheme produces very high crystal concentrations was caused by the choice in EDK09 of very high $\left(10001^{-1}\right)$ IN concentration for the $\mathrm{KC}$ scheme. It was shown here that a choice of smaller input IN concentrations yields much smaller crystal concentrations. Concentration of the nucleated crystals in the $\mathrm{KC}$ scheme is a function of the variable input IN concentration, which can be taken from the experimental data or varying the input parameters in the model for better agreement with observations.

The criticisms of the KC scheme expressed in PDA08 and EDK09 that ice nucleation and cloud glaciation occurs in the $\mathrm{KC}$ scheme in a very narrow temperature range was also incorrect. It was based on application of the KC scheme using a single value of each input parameter, e.g. contact angle, misfit strain, etc. Nucleation in a single IN size fraction with single properties for the whole fraction really yields nucleation in a temperature range of 1-3 degrees. Therefore, the $\mathrm{KC}$ scheme can be improved by averaging over some ranges of the input parameters, perhaps in the way similar to Marcoli et al. (2007). Such a smoothing of the KC scheme was demonstrated in EDK09.

Simulations performed here with the KC scheme and three IN fractions with various properties showed that ice nucleation may consist of several nucleation impulses in various $T$-ranges, so that nucleation in a mixture of IN species occurs over the temperature range of $15-20^{\circ} \mathrm{C}$. Observed cloud glaciation, when liquid phase vanishes, occurs over a similar range of $15-20^{\circ} \mathrm{C}$ in convective cases, and over much narrower $T$-ranges in stratiform cases when cloud temperature does not vary significantly. Note that the precise measurements of the temperature dependence of heterogeneous ice nucleation for a single substance have never been made. All of the experimental ice nucleation data actually relates to large ensembles of IN mixtures with various properties and various initial conditions (e.g., DeMott et al., 1998, 2003; 
Phillips et al., 2008). Conclusions on how narrow or wide the $T$-interval of nucleation for an individual aerosol type can be made only when corresponding measurements are available.

The simple model for $\mathrm{KC}$ scheme with $3 \mathrm{IN}$ species was chosen for illustration. If we have chosen more than $3 \mathrm{IN}$ species, e.g., with 7 aerosol modes as in Zubler et al. (2011), or each mode had a dispersion of contact angles, active sites and activation energies, the nucleation would be much smoother and could occur quasi-continuously and over even wider temperature range. The KC scheme does not have limitations on the number of IN species, their concentrations and properties, and allows easy incorporation of any available experimental information. The challenge is that such information very rarely (if ever) is provided by experimentalists. However, it is possible to solve the "inverse problem" in numerical simulations by varying input parameters until the simulation results become close to observations, and thereby retrieving IN properties.

Another evaluation of the $\mathrm{KC}$ scheme was performed by a comparison of the results of numerous parcel runs with $\mathrm{KC}$ ice nucleation scheme to the results of ice nuclei (nucleated crystals) measurements in six recent field campaigns and in some laboratory measurements. The results plotted as a function of the temperature or ice supersaturation show that the $\mathrm{KC}$ scheme agrees well with the experimental data on the nucleated crystals concentrations.

Increasing attention is being paid to the existence and long lifetime of the mixed-phase Arctic clouds, which has been a substantial challenge for heterogeneous ice nucleation parameterizations. Simulations of a case from the MPACE field experiment were conducted here using a single column model with spectral bin microphysics and the KC ice nucleation scheme. These simulations were able to reproduce the correct quasi-steady mixed phase of this cloud for a few hours even without invoking some additional hypothetical mechanisms. Our simulations showed that the major contribution to ice nucleation comes from the coarse aerosol mode, and contribution from the fine (CCN) mode is much smaller.

The discrepancy between the IN measured during MPACE by the CFDC instrument and the IN predicted by the KC scheme from the coarse mode aerosol concentration raises the issue of the appropriate interpretation of the IN measured by the CFDC. There are several possible reasons for not detecting these IN by the CFDC. Limitation of the aerosol diameter in CFDC by $1.5 \mu \mathrm{m}$ while measured aerosol had a second mode near $2.6 \mu \mathrm{m}$, so that the largest and most effective IN could be missed in CFDC. The process of ice nucleation via freezing may take from a few minutes to a few hours, while the processing time in the CFDC is limited to $7-15 \mathrm{~s}$ (PDA08); thus the IN captured in CFDC could have insufficient time for ice nucleation. As discussed in Sect. 1, the IN concentration $N_{\mathrm{i}, \mathrm{a}}$ should be smaller or much smaller than the total aerosol concentration $N_{\mathrm{a}}$, see Eq. (10). Of course, only a fraction of all aerosol can serve as IN, and only a fraction of total IN becomes crystals in this example,
$N_{\mathrm{c}} \ll N_{\mathrm{ai}}$, but as Eq. (10) indicates, the $N_{\mathrm{ai}}$, can be greater or much greater than the measured $N_{\mathrm{i}, \text { exp }}$ due to experimental limitations. Then, if necessary, an appropriate $N_{\mathrm{ai}}$ can be determined by its variation in the model using the MDC92, DM98, KC, DW04, LD06, PDA08 or other similar ice nucleation scheme.

Acknowledgements. The authors are grateful to Steve Klein and Renata McCoy for providing the initial data for MPACE simulations, to Jiwen Fan and Mikhail Ovtchinnikov for providing the processed aircraft data from the MPACE campaign period B, to Paul DeMott and Trude Eidhammer for providing the IN data from CFDC from 6 field campaigns, and some data of parcel model simulations with the CSU model. All of these persons and Hugh Morrison are thanked for useful discussions. The authors are grateful to Paul DeMott and two anonymous referees for reviewing the manuscript, discussions and useful remarks that improved the paper. This research was supported by a NASA MAP grant.

Edited by: A. Nenes

\section{References}

Al-Naimi, R. and Saunders, C. P. R.: Measurements of natural deposition and condensation-freezing ice nuclei with a continuous flow chamber, Atmos. Environ., 19, 1871-1882, 1985.

Barahona, D. and Nenes, A.: Parameterization of cirrus formation in large scale models: Homogenous nucleation, J. Geophys. Res., 113, D11211, doi:10.1029/2007JD009355, 2008.

Barahona, D. and Nenes, A.: Parameterizing the competition between homogeneous and heterogeneous freezing in cirrus cloud formation - monodisperse ice nuclei, Atmos. Chem. Phys., 9, 369-381, doi:10.5194/acp-9-369-2009, 2009.

Berezinsky, N. A. and Stepanov, G. V.: Dependence of natural iceforming nuclei concentration of different size on the temperature and supersaturation, Izv. Acad. Sci. USSR, Atmos. Oceanic Phys., 22, 722-727, 1986.

Bigg, E. K.: The formation of atmospheric ice crystals by the freezing of droplets, Q. J. Roy. Meteor. Soc., 79, 510-519, 1953.

Borovikov, A. M., Gaivoronsky, I. I., Zak, E. G., Kostarev, V. V., Mazin, I. P., Minervin, V. E., Khrgian, A. Kh., and Shmeter, S. M.: Cloud Physics, Leningrad, Hydrometeoizdat, 1961, Transl. by Israel Program Scientif. Translation, US Dept. Commerce, Washington, DC, 459 pp., 1963.

Boville, B. A., Rasch, P. J., Hack, J. J., and McCaa, J. R.: Representation of clouds and precipitation processes in the Community Atmosphere Model version 3 (CAM3), J. Climate, 19, 2184-2198, 2006.

Chen, J.-P., Hazra, A., and Levin, Z.: Parameterizing ice nucleation rates using contact angle and activation energy derived from laboratory data, Atmos. Chem. Phys., 8, 7431-7449, doi:10.5194/acp-8-7431-2008, 2008.

Comstock, J. M., Lin, R.-F., Starr, D. O'C., and Yang, P.: Understanding ice supersaturation, particle growth, and number concentration in cirrus clouds, J. Geophys. Res., 113, D23211, doi:10.1029/2008JD010332, 2008.

Cooper, W. A.: Ice initiation in natural clouds. In: Precipitation Enhancement - a scientific challenge, Meteor. Monogr., 21, Amer. Meteor. Soc., Boston, 29-32, 1986. 
Cotton, W. R. and Anthes, R. A.: Storm and Cloud Dynamics, Academic Press, New York, 883 pp., 1989.

Cotton, W. R., Pielke Sr., R. A., Walko, R. L., Liston, G. E., Tremback, C. J., Jiang, H., McAnelly, R. L., Harrington, J. Y., Nicholls, M. E., Carrio, G. G., and McFadden, J. P.: RAMS 2001: Current status and future directions, Meteor. Atmos. Phys., 82, 5-29, 2003.

Curry, J. A.: Interactions among turbulence, radiation and microphysics in Arctic stratus clouds, J. Atmos. Sci., 43, 525-538, 1986.

Curry, J. A. and Webster, P. J.: Thermodynamics of Atmospheres and Oceans, Academic Press, London, 467 pp., 1999.

Curry, J. A., Meyer, F. G., Radke, L. F., Brock, C. A., and Ebert, E. E.: Occurrence and characteristics of lower tropospheric ice crystals in the Arctic, Int. J. Climatol., 10, 749-764, 1990.

Curry, J. A., Schramm, J., and Ebert, E. E.: Impact of clouds on the surface radiation budget of the Arctic Ocean, Meteorol. Atmos. Phys., 51, 197-217, 1993.

Curry, J. A., Rossow, W. B., Randall, D., and Schramm, J. L.: Overview of Arctic cloud and radiation properties, J. Climate, 9, 1731-1764, 1996.

Curry, J. A., Hobbs, P. V., King, M. D., Randall, D. A., Minnis, P., Isaac, G. A., Pinto, J. O., Uttal, T., Bucholtz, A., Cripe, D. G., Gerber, H., Fairall, C. W., Garrett, T. J., Hudson, J., Intrieri, J. M., Jacob, C., Jensen, T., Lawson, P., Marcotte, D., Nguyen, L., Pilewskie, P., Rangno, A., Rogers, D. C., Strawbridge, K. B., Valero, F. P. J., Williams, A. G., and Wylie, D.: FIRE Arctic Clouds Experiment, B. Am. Meteorol. Soc., 81, 5-29, 2000.

Dash, J. G., Fu, H., and Wettlaufer, J. S.: The premelting of ice and its environmental consequences, Rep. Progr. Phys., 58, 115-167, 1995.

Defay, R., Prigogine, I., and Bellemans, A.: Surface Tension and Absorption, Wiley, New York, 1966.

DeMott, P. J., Rogers, D. C., Kreidenweis, S. M., Chen, Y., Twohy, C. H., Baumgardner, D., Heymsfield, A. J., and Chan, K. R.: The role of heterogeneous freezing nucleation in upper tropospheric clouds: Inferences from SUCCESS, Geophys. Res. Lett., 25, 1387-1390, 1998.

DeMott, P. J., Cziczo, D. J., Prenni, A. J., Murphy, D. M., Kreidenweis, S. M., Thomson, D. S., Borys, R., and Rogers, D. C.: Measurements of the concentration and composition of nuclei for cirrus formation, P. Natl. Acad. Sci., 100, 14655-14660, 2003.

DeMott, P. J., Prenni, A. J., Liu, X., Kreidenweis, S. M., Petters, M. D., Twohy, C. H., Richardson, M. S., Eidhammer, T., and Rogers, D. C.: Predicting global atmospheric ice nuclei distributions and their impacts on climate, P. Natl. Acad. Sci. USA, 107, 1121711222, doi:10.1073/pnas.0910818107, 2010.

Diehl, K. and Wurzler, S.: Heterogeneous drop freezing in the immersion mode: Model calculations considering soluble and insoluble particles in drops, J. Atmos. Sci., 61, 2063-2072, 2004.

Dufour, L. and Defay, R.: Thermodynamics of Clouds, Academic Press, New York, 1963.

ECMWF-2007: European Centre for Medium Range Weather Forecast (ECMWF): IFS documentation cycle 31rl, Part IV: Physical processes, $155 \mathrm{pp}$., available at: http://www.ecmwf.int/research/ ifsdocs/CY31r1/index.html, last access: 17 November 2009, 2007.

Eidhammer, T., DeMott, P. J., and Kreidenweis, S. M.: A comparison of heterogeneous ice nucleation parameterization using a parcel model framework, J. Geophys. Res., 114, D06202, doi:10.1029/2008JD011095, 2009.

Fan, J., Ovtchinnikov, M., Comstock, J. M., McFarlane, S. A., and Khain, A.: Ice formation in Arctic mixed-phase clouds: Insights from a 3-D cloud-resolving model with size-resolved aerosol and cloud microphysics, J. Geophys. Res., 114, D04205, doi:10.1029/2008JD010782, 2009.

Fletcher, N. H.: The Physics of Rainclouds, Cambridge University Press, Cambridge, UK, 390 pp., 1962.

Fletcher, N. H.: Active sites and ice crystal nucleation, J. Atmos. Sci., 26, 1266-1278, 1969.

Fridlind, A. M., Ackerman, A. S., McFarquhar, G., Zhang, G., Poellot, M. R., DeMott, P. J., Prenni, A. J., and Heymsfield, A. J.: Ice properties of single-layer stratocumulus during the Mixed-Phase Arctic Cloud Experiment: 2. Model Results, J. Geophys. Res., 112, D24202, doi:10.1029/2007JD008646, 2007.

Gettelman, A., Morrison, H., and Ghan, S. J.: A new two-moment bulk stratiform cloud microphysics scheme in the Community Atmosphere Model, Version 3 (CAM3). Part II: Single-Column and Global Results, J. Climate, 21, 3660-3679, 2008.

Gierens, K.: On the transition between heterogeneous and homogeneous freezing, Atmos. Chem. Phys., 3, 437-446, doi:10.5194/acp-3-437-2003, 2003.

Gultepe, I., Isaac, G., Judak, D., Nissen, R., and Strapp, J. W.: Dynamical and microphysical characteristics of Arctic clouds during BASE, J. Climate, 13, 1225-1254, 2000.

Heymsfield, A. J. and Sabin, R. M.: Cirrus crystal nucleation by homogeneous freezing of solution droplets, J. Atmos. Sci., 46, 2252-2264, 1989.

Hobbs, P. V.: Ice Physics, Clarendon Press, Oxford, 837 pp., 1974.

Hobbs, P. V. and Rangno, A. L.: Rapid development of high ice particle concentrations in small polar maritime cumuliform cloud, J. Atmos. Sci., 47, 2710-2722, 1990.

Huffman, P. J.: Supersaturation spectra of AgI and natural ice nuclei, J. Appl. Meteorol., 12, 1080-1082, 1973.

Huffman, P. J. and Vali, G.: The effect of vapor depletion on ice nucleus measurements with membrane filter, J. Appl. Meteorol., 12, 1018-1024, 1973.

Intrieri, J. M., Shupe, M. D., Uttal, T., and McCarty, B. J.: Arctic cloud statistics from radar and lidar at SHEBA, J. Geophys., Res., 107, 8030-8039, 2002.

Kärcher, B. and Lohmann, U.: A parameterization of cirrus cloud formation: Heterogeneous freezing, J. Geophys. Res., 108, 4402, doi:10.1029/2002JD003220, 2003.

Kashchiev, D.: Nucleation: Basic Theory with Applications, Batterworth-Heineman, Oxford, 512 pp., 2000.

Kashchiev, D., Borissova, A., Hammond, R. B., and Roberts, K. J.: Effect of cooling rate on the critical undercooling for crystallization, J. Cryst. Growth, 312, 698-704, 2010.

Khairoutdinov, M. F. and Khvorostyanov, V. I.: Mathematical modeling of an artificially induced by seeding decrease of the optical thickness of orographic clouds, Atmos. Optics, 3, 701-708, 1989.

Khvorostyanov, V. I.: Mesoscale processes of cloud formation, cloud-radiation interaction and their modelling with explicit cloud microphysics. Review, Atmos. Res., 39, 1-67, 1995.

Khvorostyanov, V. I and Curry, J. A.: A new theory of heterogeneous nucleation for application in cloud and climate models, Geophys. Res. Lett., 27, 4081-4084, 2000. 
Khvorostyanov, V. I. and Curry, J. A.: Thermodynamic theory of freezing and melting of water and aqueous solutions, J. Phys. Chem. A, 108, 11073-11085, 2004a.

Khvorostyanov, V. I. and Curry, J. A.: The theory of ice nucleation by heterogeneous freezing of deliquescent mixed CCN. Part 1: Critical radius, energy and nucleation rate, J. Atmos. Sci., 61, 2676-2691, 2004b.

Khvorostyanov, V. I. and Curry, J. A.: The theory of ice nucleation by heterogeneous freezing of deliquescent mixed CCN. Part 2: Parcel model simulation, J. Atmos. Sci., 62, 261-285, 2005.

Khvorostyanov, V. I. and Curry, J. A.: Aerosol size spectra and CCN activity spectra: Reconciling the lognormal, algebraic, and power laws, J. Geophys. Res., 111, D12202, doi:10.1029/2005JD006532, 2006.

Khvorostyanov, V. I. and Curry, J. A.: Refinements to the Köhler's theory of aerosol equilibrium radii, size spectra, and droplet activation: Effects of humidity and insoluble fraction, J. Geophys. Res., 112, D05206, doi:10.1029/2006JD007672, 2007.

Khvorostyanov, V. I. and Curry, J. A.: Critical humidities of homogeneous and heterogeneous ice nucleation: inferences from extended classical nucleation theory, J. Geophys. Res., 114, D04207, doi:10.1029/2008JD011197, 2009.

Khvorostyanov, V. and Sassen, K.: Towards the theory of homogeneous nucleation and its parameterization for cloud models, Geophys. Res. Lett., 25, 3155-3158, 1998.

Khvorostyanov, V. I., Curry, J. A., Pinto, J. O., Shupe, M., Baker, B., and Sassen, K.: Modeling with explicit spectral water and ice microphysics of a two-layer cloud system of altostratus and cirrus observed during the FIRE Arctic Clouds Experiment, Special Issue, J. Geophys. Res., 106, 15099-15112, 2001.

Khvorostyanov, V. I., Curry, J. A., Gultepe, I., and Strawbridge, K.: A springtime cloud over the Beaufort Sea polynya: Threedimensional simulation with explicit spectral microphysics and comparison with observations, J. Geophys. Res., 108, 4296, doi:10.1029/2001JD001489, 2003.

Khvorostyanov, V. I., Morrison, H., Curry, J. A., Baumgardner, D., and Lawson, P.: High supersaturation and modes of ice nucleation in thin tropopause cirrus: Simulation of the 13 July 2002 Cirrus Regional Study of Tropical Anvils and Cirrus Layers case, J. Geophys. Res., 111, D02201, doi:10.1029/2004JD005235, 2006.

Klein, S., Fridlind, A., McCoy, R. B., McFarquhar, G., Menon, S., Morrison, H., Veron, D., Xie, S., Yio, J. J., and Zhang, M.: GCSS Polar Cloud WG SCM/CRM/LES Intercomparison Case 2004, ARM Mixed-Phase Arctic Cloud Experiment (M-PACE): 5-22 October 2004, available at: http://science.arm.gov/wg/cpm/scm/ scmic5/, last access: 15 December 2009, 2006.

Klein, S. A., McCoy, R. B., Morrison, H., Ackerman, A. S., Avramov, A., de Boer, G., Chen, M., Cole, J. N. S., Del Genio, A. D., Falk, M., Foster, M. J., Fridlind, A., Golaz, J.-C., Hashino, T., Harrington, J. Y., Hoose, C., Khairoutdinov, M. F., Larson, V. E., Liu, X., Luo, Y., McFarquhar, G. M., Menon, S., Neggers, R. A. J., Park, S., Poellot, M. R., Schmidt, J. M., Sednev, I., Shipway, B. J., Shupe, M. D., Spangenberg, D. A., Sud, Y. C., Turner, D. D., Veron, D. E., von Salzen, K., Walker, G. K., Wang, Z., Wolf, A. B., Xie, S., Xu, K.-M., Yang, F., and Zhango, G.: Intercomparison of model simulations of mixed-phase clouds observed during the ARM Mixed-Phase Arctic Cloud Experiment. I. Single-layer cloud, Q. J. Roy. Meteor. Soc., 135, 979-1002,
2009.

Kondratyev, K. Ya., Ovtchinnikov, M. V., and Khvorostyanov, V. I.: Mesoscale model of mixed-phase cloud development with account for the interaction among optical, radiative and microphysical processes, Atmos. Optics, 3, 639-646, 1990a.

Kondratyev, K. Ya., Ovtchinnikov, M. V., and Khvorostyanov, V. I.: Modeling the evolution of optical, radiative and microphysical properties of the atmosphere after crystallization of cloudiness. Part I: Complete dispersal of the clouds, Atmos. Optics, 3, 647654, 1990b.

Kondratyev, K. Ya., Ovtchinnikov, M. V., and Khvorostyanov, V. I.: Modeling the evolution of optical, radiative and microphysical properties of the atmosphere after crystallization of cloudiness. Part II: Restoration of the clouds after dispersal, Atmos. Optics, 3, 655-661, 1990c.

Korolev, A., Isaac, G., Cober, S. G., Strapp, J. W., and Hallett, J.: Microphysical characterization of mixed-phase clouds, Q. J. Roy. Meteor. Soc., 129, 19-38, 2003.

Landau, L. D. and Lifshitz, E. M.: Statistical Physics, Part 1, Pergamon Press, New York, 1980.

Lawson, R. P., Baker, B. A., Schmitt, C. G., and Jensen, T. L.: Overview of microphysical properties of summertime boundary layer clouds observed during FIRE.ACE, J. Geophys. Res., 106, 14989-15014, 2001.

Lin, R.-F., Starr, D. O'C., DeMott, P. J., Cotton, R., Sassen, K., Jensen, E., Kärcher, B., and Liu, X.: Cirrus parcel model comparison project. Phase 1: The critical components to simulate cirrus initiation explicitly, J. Atmos. Sci., 59, 2305-2329, 2002.

Liu, X. and Penner, J.: Ice nucleation parameterization for global models, Meteorol. Zeitschr., 14, 499-514, 2005.

Liu, X., Penner, J. E., Ghan, S. J., and Wang, M.: Inclusion of ice microphysics in the NCAR Community Atmospheric Model version 3 (CAM3), J. Climate, 20, 4526-4547, 2007.

Lohmann, U. and Diehl, K.: Sensitivity studies of the importance of dust ice nuclei for the indirect aerosol effect on stratiform mixedphase clouds, J. Atmos. Sci., 63, 968-982, 2006.

Marcolli, C., Gedamke, S., Peter, T., and Zobrist, B.: Efficiency of immersion mode ice nucleation on surrogates of mineral dust, Atmos. Chem. Phys., 7, 5081-5091, doi:10.5194/acp-7-50812007, 2007.

McFarquhar, G. M., Zhang, G., Poellot, M., Kok, G., McCoy, R., Tooman, T., Fridlind, A., and Heymsfield, A. J.: Ice properties of single-layer stratocumulus during the Mixed-Phase Arctic Cloud Experiment: 1. Observations, J. Geophys. Res., 112, D24201, doi:10.1029/2007JD008633, 2007.

Meyers, M. P., DeMott, P. J., and Cotton, W. R.: New primary icenucleation parameterizations in an explicit cloud model, J. Appl. Meteor., 31, 708-721, 1992.

Möhler, O., Field, P. R., Connolly, P., Benz, S., Saathoff, H., Schnaiter, M., Wagner, R., Cotton, R., Krämer, M., Mangold, A., and Heymsfield, A. J.: Efficiency of the deposition mode ice nucleation on mineral dust particles, Atmos. Chem. Phys., 6, 3007-3021, doi:10.5194/acp-6-3007-2006, 2006.

Morrison, H. and Gettelman, A.: A new two-moment bulk stratiform cloud microphysics scheme in the community atmosphere model, Version 3 (CAM3). Part I: Description and numerical tests, J. Climate, 21, 3642-3659, 2008.

Morrison, H. and Pinto, J. O.: Mesoscale modeling of springtime arctic mixed-phase stratiform clouds using a new two-moment 
bulk microphysics scheme, J. Atmos. Sci., 62, 3683-3704, 2005.

Morrison, H., Curry, J. A., and Khvorostyanov, V. I.: A new doublemoment microphysics parameterization. Part 1: Description, J. Atmos. Sci., 62, 1665-1674, 2005.

Morrison, H., Pinto, J. O., Curry, J. A., and McFarquhar, G. M.: Sensitivity of modeled arctic mixed-phase stratocumulus to cloud condensation and ice nuclei over regionally varying surface conditions, J. Geophys. Res., 113, D05203, doi:10.1029/2007JD009729, 2008.

Morrison, H., McCoy, R. B., Klein, S. A., Xie, S., Luo, Y., Avramov, A., Chen, M., Cole, J. N. S., Falk, M., Foster, M. J., Del Genio, A. D., Harrington, J. Y., Hoose, C., Khairoutdinov, M. F., Larson, V. E., Liu, X., McFarquhar, G. M., Poellot, M. R., von Salzen, K., Shipway, B. J., Shupe, M. D., Sud, Y. C., Turner, D. D., Veron, D. E., Walker, G. K., Wang, Z., Wolf, A. B., Xu, K.-M., Yang, F., and Zhang, G.: Intercomparison of model simulations of mixed-phase clouds observed during the ARM MixedPhase Arctic Cloud Experiment. II. Multilayer cloud, Q. J. Roy. Meteor. Soc., 135, 1003-1019, 2009.

Philips, V. T. J., DeMott, P. J., and Andronache, C.: An empirical parameterization of heterogeneous ice nucleation for multiple chemical species of aerosol, J. Atmos. Sci., 65, 2757-2783, 2008.

Prenni, A. J., Harrington, J. Y., Tjernström, M., DeMott, P. J., Avramov, A., Long, C. N., Kreidenweis, S. M., Olsson, P. Q., and Verlinde, J.: Can ice-nucleating aerosols affect Arctic seasonal climate?, B. Am. Meteor. Soc., 88, 541-550, 2007.

Pruppacher, H. R. and Klett, J. D.: Microphysics of Clouds and Precipitation, 2nd Edn., Kluwer, Dordrecht, The Netherlands, 997 pp., 1997.

Rangno, A. L. and Hobbs, P. V.: Ice particle concentrations and precipitation development in small polar maritime cumuliform clouds, Q. J. Roy. Meteor. Soc., 117, 207-241, 1991.

Rogers, D. C.: Field and laboratory studies of ice nucleation in winter orographic clouds, Ph.D. dissertation, Dept. Atmospheric Science, Univ. of Wyoming, Laramie, 161 pp., 1982.

Rogers, D. C.: Development of a continuous flow thermal gradient diffusion chamber for ice nucleation studies, Atmos. Res., 22, 149-181, 1988.

Sassen, K.: Ice nuclei availability in the higher tropospheric: implications of a remote sensing cloud phase climatology, in: Nucleation and Atmospheric aerosols, edited by: Fukuta, N. and Wagner, P., Deepak Publishing, Hampton, Virginia, 287-290, 1992.

Sassen, K. and Benson, S.: Ice nucleation in cirrus clouds, A model study of the homogeneous and heterogeneous nucleation modes, Geophys. Res. Lett., 27, 521-524, 2000.

Sassen, K. and Dodd, G. C.: Haze particle nucleation simulation in cirrus clouds, and application for numerical and lidar studies, J. Atmos. Sci., 46, 3005-3014, 1989.

Sassen, K. and Khvorostyanov, V. I.: Microphysical and radiative properties of mixed-phase altocumulus: A model evaluation of glaciation effects, Atmos. Res., 84, 390-398, 2007.

Sassen, K. and Khvorostyanov, V. I.: Indirect cloud effects from boreal forest fire smoke: evidence for ice nucleation from polarization lidar data and cloud model simulations. Environ. Res. Lett., 3, 025006, doi:10.1088/1748-9326/3/2/025006, 2008.
Sassen, K., Wang, Z., Khvorostyanov, V. I., Stephens, G. L., and Bennedetti, A.: Cirrus cloud ice water content radar algorithm evaluation using an explicit cloud microphysical model, J. Appl. Meteorol., 41, 620-628, 2002.

Seinfeld, J. H. and Pandis, S. N.: Atmospheric Chemistry and Physics, Wiley, New York, 1326 pp., 1998.

Shupe, M. D., Matrosov, S. Y., and Uttal, T.: Arctic mixed-phase cloud properties derived from surface-based sensors at SHEBA, J. Atmos. Sci., 63, 697-711, 2006.

Thomson, J. J.: Application of Dynamics to Physics and Chemistry, 1st Edn., Cambridge University Press, London, 163 pp., 1888.

Vali, G.: Nucleation terminology, J. Aerosol. Sci., 16, 575-576, 1985.

Vehkamäki, H., Määttänen, A., Lauri, A., Napari, I., and Kulmala, M.: Technical Note: The heterogeneous Zeldovich factor, Atmos. Chem. Phys., 7, 309-313, doi:10.5194/acp-7-309-2007, 2007.

Verlinde, J., Harrington, J. Y., McFarquhar, G. M., Yannuzzi, V. T., Avramov, A., Greenberg, S., Johnson, N., Zhang, G., Poellot, M. R., Mather, J. H., Turner, D. D., Eloranta, E. W., Zak, B. D., Prenni, A. J., Daniel, J. S., Kok, G. L., Tobin, D. C., Holz, R., Sassen, K., Spangenberg, D., Minnis, P., Tooman, T. P., Ivey, M. D., Richardson, S. J., Bahrmann, C. P., Shupe, M. D., DeMott, P. J., Heymsfield, A. J., and Schofield, R.: Overview of the Mixed-Phase Arctic Cloud Experiment (MPACE), B. Am. Meteorol. Soc., 88, 205-201, 2007.

Xie, S., Klein, S. A., Yio, J. J., Beljaars, A. C. M., Long, C. N., and Zhang, M.: An assessment of ECMWF analyses and model forecasts over the North Slope of Alaska using observations from the ARM Mixed-Phase Arctic Cloud Experiment, J. Geophys. Res., 111, D05107, doi:10.1029/2005JD006509, 2006a.

Xie, S., Klein, S. A., Zhang, M., Yio, J. J., Cederwall, R. T., and McCoy, R.: Developing large-scale forcing data for single-column and cloud-resolving models from the MixedPhase Arctic Cloud Experiment, J. Geophys. Res., 111, D19104, doi:10.1029/2005JD006950, 2006b.

Yum, S. S. and Hudson, J. G.: Vertical distributions of cloud condensation nuclei spectra over the springtime Arctic Ocean, J. Geophys. Res., 106, 15045-15052, 2001.

Zeldovich, J. B.: Toward the theory of formation of a new phase. Cavitation, J. Exper. Theor. Phys., 12, 525-538, 1942.

Zhang, H., Sokolik, I. N., and Curry, J. A.: Impact of dust aerosols on Hurricane Helene's early development through the deliquescent heterogeneous freezing mode, Atmos. Chem. Phys. Discuss., 11, 14339-14381, doi:10.5194/acpd-11-14339-2011, 2011.

Zubler, E. M., Lohmann, U., Lüthi, D., and Schär, C.: Statistical analysis of aerosol effects on simulated mixed-phase clouds and precipitation in the Alps, J. Atmos. Sci., 68, 1474-1492, 2011. 